\title{
On the Geotechnical Modeling of High-Level Nuclear Waste Disposal by Rock Melting
}

\author{
Francois E. Heuze
}

Manuscript date: December 1981

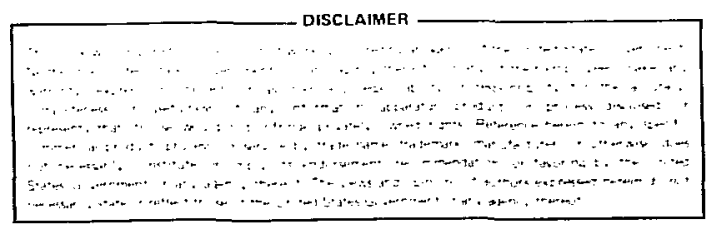

\section{LAWRENCE LIVERMORE LABORATORY} University of California - Livermore, California • 94550 


\section{GN THE GEOTECENICAL MODELING}

OF HIGH-LEVEL NUCLEAR WASTE DISPOSAL,

BY ROCK MELTING

\section{ABSTRACT}

A new strategy has been developed for the geotechnical modeling of nuclear waste disposal by rock melting (DRM). Three separate tasks were performed to reach this objective:

- A review of the four scenarios which have been proposed for DRM, to date.

- An evaluation of computer-based numerical models which could be used to analyze the mechanical, thermal, and hydraulic processes involved in DRM.

- A critical review of rock mass properties which are relevant to the design and safety of waste di rosal by rock melting.

It is concluded that several geotechnical aspects of DRM can be studied realistically with current state-of-the-art model capabilities and knowledge of material properties. The next step in the feasibility study of DRM should be a best-estimate calculation of the four cavity-melt and canister-burial concepts. These new analyses will indicate the most critical areas for subsequent research. 


\section{INTRODUCTION}

\subsection{HIGH-LEVEL NOCLEAR WASTE DISPOSAL}

The various options which have been discussed for permanent disposal of high-level nuclear waste include:

- Transmutation

- Separation

- Extended storage

- Extraterrestrial

- Geologic disposal

- Antarctic rock

- Ice sheets

- Seabed

- Mined cavities

- Rock melting

and possible combinations of the above.

Today, the favored option is permanent geologic disposal in mined cavities. $^{1}$ It is the object of extensive geological, geotechnical, and geochemical studies. ${ }^{2,3}$ as an alternative to this option, the concept of disposal by rock melting (DRM) also has received some attention. 4-11 This research is part of a continuing effort to try and assess the feasibility and the merits of DRM. In particular, the discussions will focus upon the geotechnical model studies which would be used in support of rock melting disposal. Both numerical and physical models can be considered. With numerical models, special attention must be given to the seiection of realistic input values for in situ conditions and for material properties.

In the remainder of this section, we review the various roak melting scenarios and outline the geomechanics involved in the DRH option. In Section 2, we summarize the results of model studies performed by others. In Section 3, we review numerical models for thermal, mechanical, and hydraul:.c analysis and discuss their relevance and applicability in the current context. We also attempt to outline a strategy for future numerical calculations. In section 4, we turn to the rock mass properties required as an input to DRM analyses. We focus upon granite as a candidate host rock and evaluate the state of knowledge of relevant granite properties over a wide 
range of temperature and pressure. Other candidate rocks which also have been mentioned include basalt, salt, and shale. Carbonate rocks have been rejected because of their capacity to generate large quantities of gas when melting. Such gases would be undesirable because they would provide an additional vehicle by which radioactivity can escape into the biosphere. It is expected that this research also may benefit studies of DRM in rocks other than granite.

\subsection{SCENARIOS FOR WASTE DISPOSAL BY ROCK MELTING}

The basic idea behind DRM is to deposit the nuclear waste into the rock mass with such a power output that the rock initially will melt. Whether the waste is encapsulated or not, it will eventually be held in a matrix formed upon resolidification of the rock. Such a matrix would have a high resistance to water leaching. In addition, the high temperatures created in DRM would tend to keep the water away for many years, allowing a strong decay of the radioactive elements before water access.

Four variations of DRM have been proposed, so far.

- The first scenario, called the DUMP (Deep Underground Melt Process) concept, was introduced by the Lawrence Livermore National Laboratory. 4-6 As illustrated in Figs. 1 and 2, the waste is injected into a rock cavity 2 to $4 \mathrm{~km}$ deep. When injection and cooling stop, the rock starts to melt. Eventually, one obtains a resolidified mixture of rock and waste. The cavity may be mined conventionally or created by a nuclear explosion. Using DUMP, large volumes of waste would be disposed of in each cavity: $200 \mathrm{~m}^{3}$ of 10-yr-old dry solid waste would have a power output of several tens of megawatts.

- Deep Self Burial was proposed as an alternative by Sandia Laboratories. 7,8 Waste, encapsulated in containers heavier than the rock, would be lowered in cased holes, at least $2 \mathrm{~km}$ deep, while being cooled. They would be released after disconnecting the cooling system. Then, they would melt their way down to even greater dept:h. A large number of capsules could be released from the same hole.

- Deep Rock Disposal was also a suggestion by Sandia Laboratories. 9,10 The concept, illustrated in Fig. 3, combines elements from the previous two scenarios. The waste is not packed 


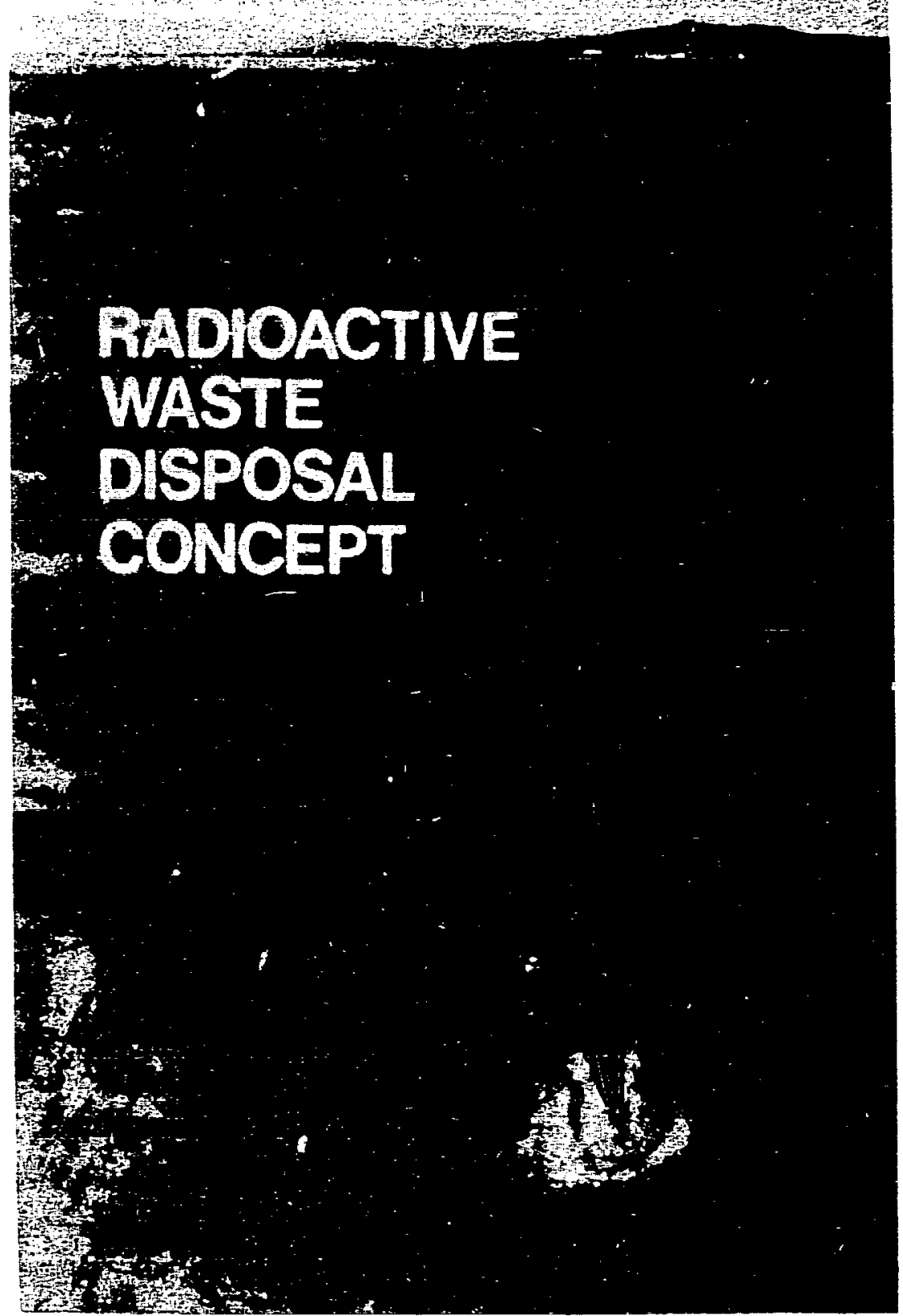

FIG. 1. DUMP concept of rock melt waste disposal.4,6 


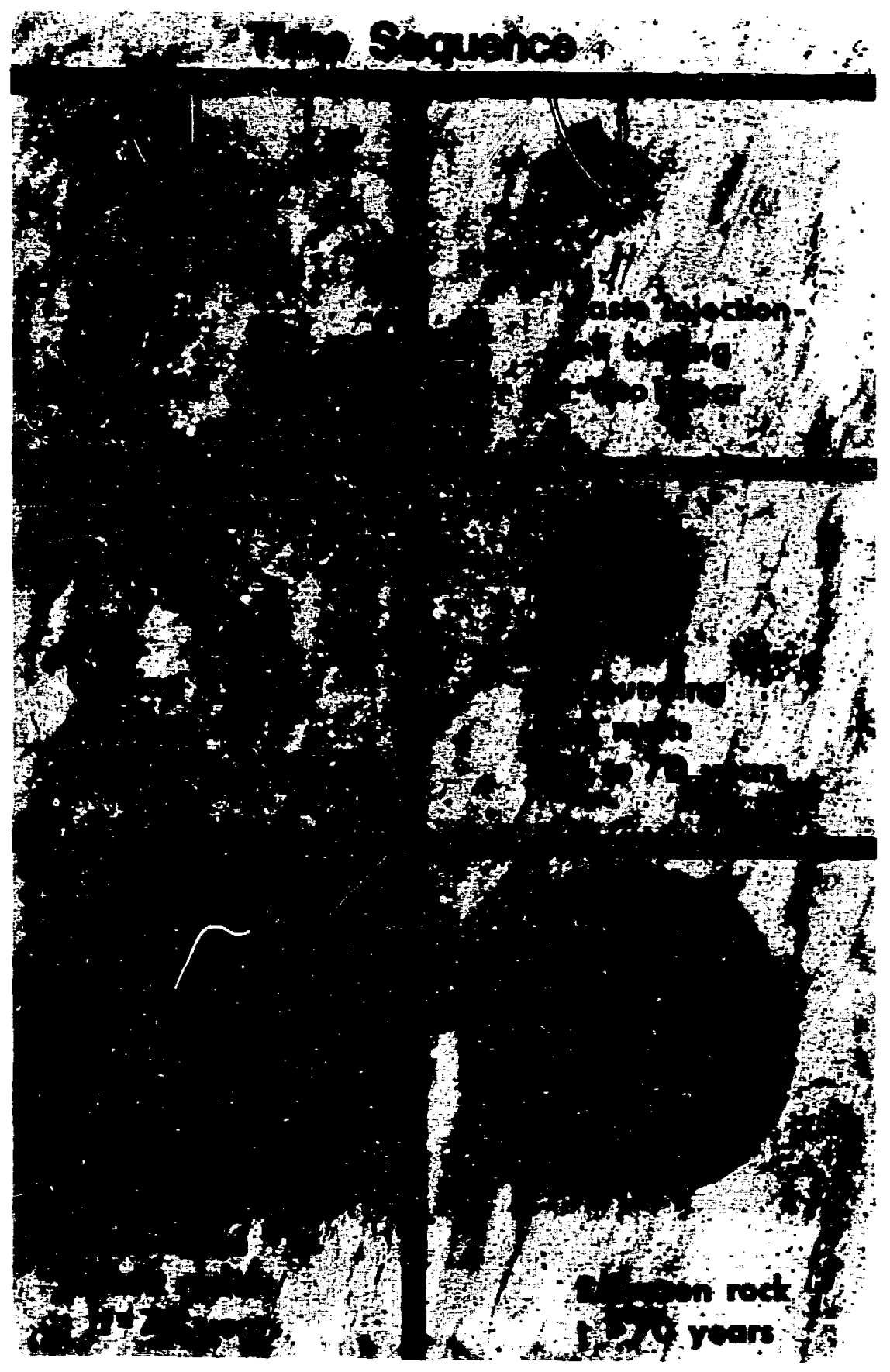

FIG. 2. DUMP concept for rock melt waste disposal. 6 


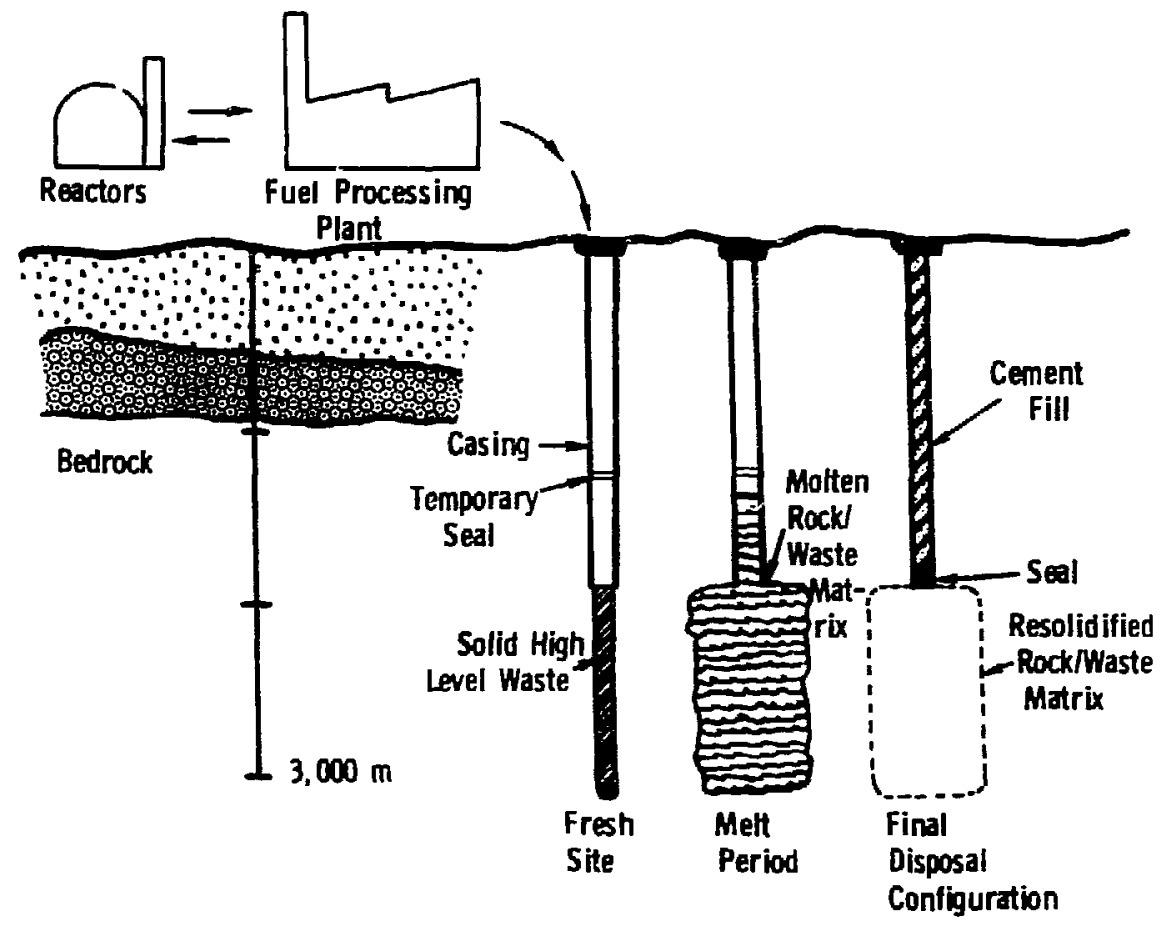

FIG. 3. Deep rock waste disposal with rock melt concept. 9

into containers, but rather it is injected into deep drill holes where it melts the surrounding rock, which eventually resolidifies. The waste vol.me in each hole is smaller than in a DUMP cavity. - Finally, in the Solidified Waste In Situ Melting Concept, ${ }^{11}$ illustrated in Figs. 4 and 5 , the waste canisters are dispersed in rock rubble inside a cavity. A lower thermal loading is achieved; this avoids possible excessive temperatures which could lead to thermal decomposition and volatilization of the rock. Also, the voids in the backfill. provide space for the expansion of the rock during melting, thus reducing the possibility of excessive stresses and fractures in the surrounding formations.

We note that all the DRM scenarios imply tirat retrieving the waste generally would be very difficult, if not impossible, and could not seriously be contemplated in the cases of deeper cavities. Such a drawback can be mitigated if the final resolidified matrix showed a very high resistance to water leaching, leading to acceptable concentrations of radioactivity release. These important geochemical matters however are beyond the szope of our geotechnical report. 

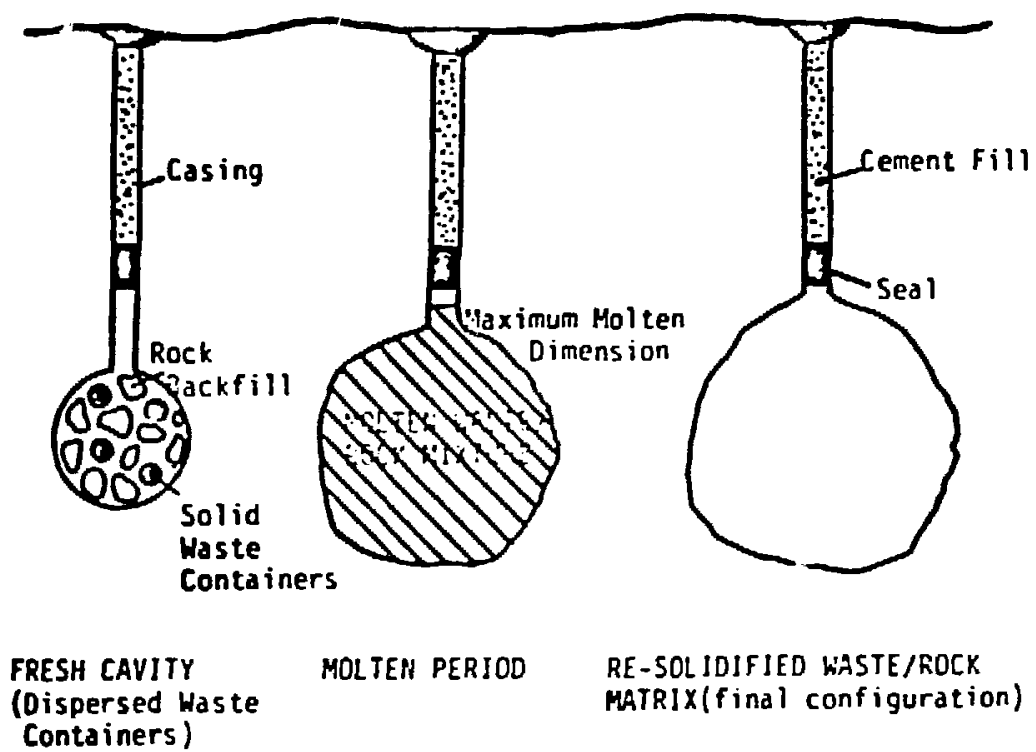

FIG. 4. Solidified waste in situ melting concept, melting sequence. II

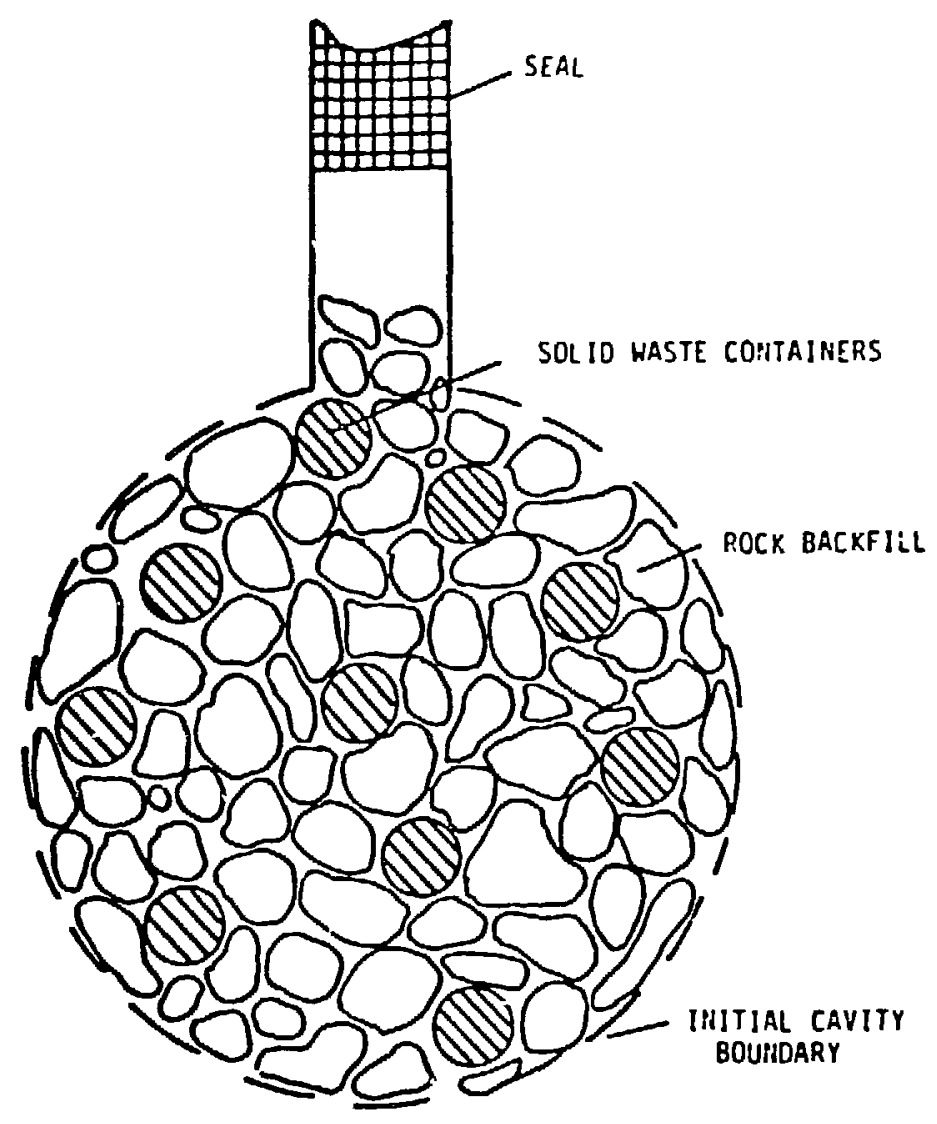

FIG. 5. Initial waste and rock backfill cavity condition in the above concept. 11 
The phenomena involved in melting scenarios have geological, thermal, mechanical, and flow/creep aspects. The rock formations will heat up, fracture, melt, and.flow, because of heating, cooling, or phase change expansion of the rock. Fluids such as the molten rock, the water, its vapor, and possibly other gases, will migrate through natural and induced connected voids. With regard to safety, contaiment, and environmental impact, questions arise in the following geotechnical areas:

- The time history of temperature distributions in the ground.

- The shape and size of the molten zone.

- The pressure of gases and fluids in and around the molten zone.

- The extent and nature of fracturing created in the rock mass.

- The extent of possible migration of melt and gases through the fractures.

It is clear that the modeling of the rock mass response requires extensive knowledge of the environment and of material properties. A nonexhaustive list of input required for analysis can be arranged under the following headings:

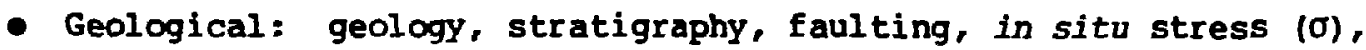
water content $(w)$.

- Thermal: time dependent power of the heat source (q), initial temperature $\left(T_{0}\right)$, thermal expansion $(\alpha)$, thermal conductivity $(k)$, thermal diffusivity $(K)$, melting temperature $\left(T_{m}\right)$, specific hest $\left(C_{p}\right)$, latent heat of fusion (L).

- Mechanical: modulus (E), Poisson's ratio (V), compressibility ( $B$ ), porosity $(\Phi)$, permeability $(K)$, density $(\rho)$, strength (cohesion, friction, tensile strength), fracture toughness $\left(\mathrm{R}_{c}\right)$.

- Flow/creep: viscosity $(\mu)$, activation energy $(Q)$.

Additional aspects of the models include possible anisotropy, temperature dependence, and pressure dependence of numerous properties. Also, it is certain that the mechanical, thermal, and flow phenomena involved in DRM are strongly coupled. Figure 6 illustrates the nature of such couplings. 12 Some of the geotechnical issues in DRM already have been addressed, although none appears to have been resolved. In the next section we review the studies by other investigators. 


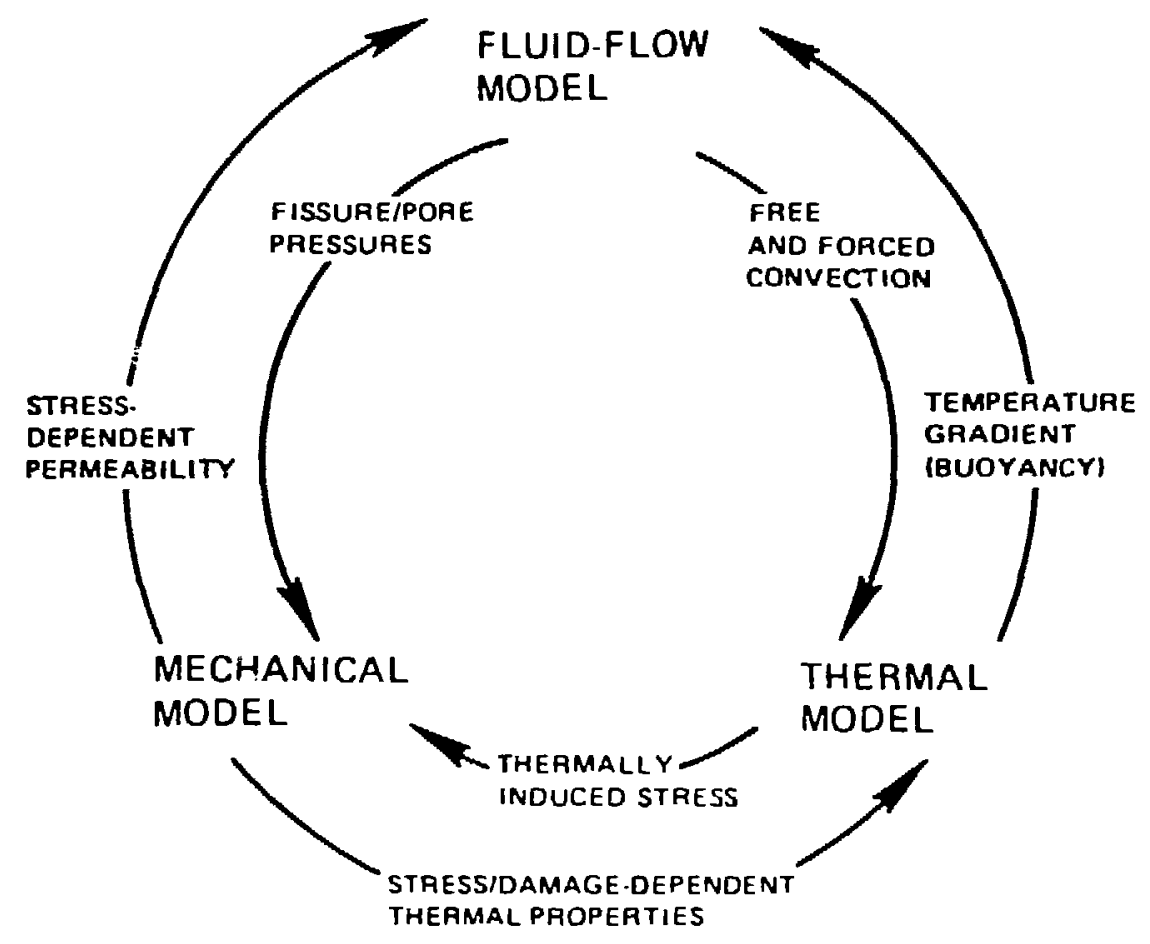

FIG. 6. Thermal-mechanical-hydraulic coupling of models. 12 


\subsection{THE DUMP SCENARIO}

In the original proposal, 4,5 the power loading was the highest of any scenario to date. An axisymmetric analytical code, BEAT, was developed to provide the balance between heat production due to the waste and heat loss by conduction. Latent heat of rock fusion was included. The material properties were chosen as follows:

- Initial temperature $=50^{\circ} \mathrm{C}$

- In situ density $=2.7 \mathrm{~g} / \mathrm{cm}^{3}$

- Melting point $=1050^{\circ} \mathrm{C}$

- Heat of fusion $=80 \mathrm{cal} / \mathrm{g}$

- Specific heat $=0.215+\left(9.60 \cdot 10^{-5} \mathrm{~T}\right)-\left(2.91 \cdot 10^{3} \mathrm{~T}^{-2}\right)$ ( $T$ in ${ }^{\circ} \mathrm{K}$ ) $\mathrm{cal} / \mathrm{g}^{\circ}{ }^{\circ} \mathrm{C}$

- Thermal conductivity $=\left(6.30 \cdot 10^{-3}\right)-\left(6.7 \cdot 10^{-6} \mathrm{~T}\right)$ $+\left(3.41 \cdot 10^{-9} \mathrm{~T}^{2}\right)\left(\mathrm{T}\right.$ in $\left.{ }^{\circ} \mathrm{C}\right) \mathrm{cal} / \mathrm{cm}-\mathrm{s}-{ }^{\circ} \mathrm{C}$.

Heat flow calculations were performed for various conditions. A typical calculation used the following assumptions:

- Chimney formed by a 5-kt explosive at a 2000-m depth (11-m radius).

- Age of waste $=0.5 \mathrm{yr}$ (post-irradiation time) .

- Rate of waste addition $=1500$ ton/yr. (The waste from each ton of fuel would be contained in $400 \mathrm{gal}$ of solution at a temperature of $99^{\circ} \mathrm{C}$. )

- Duration of waste addition $=25 \mathrm{yr}$.

- Chimney temperature kept at $200^{\circ} \mathrm{C}$ during waste addition.

- Waste and water addition terminated at 25 yr.

Selected results are presented in Fig. 7. One notes the peak power output of $67 \mathrm{MW}$ and a maximum melt radius of $96 \mathrm{~m}$ after $90 \mathrm{yr}$. Possible cavity migration was dismissed based on the argument that even if directional growth were to occur, the increased rate of conductive heat loss would praclude the possibility of movement over a significant distance; hence, any process of growth or movement would necessarily be self-limiting. 5 In a subsequent HEAT calculation, the power output was significantly decreased, giving a peak value of $23 \mathrm{MN}$. Also, the waste-loading period was shortened considerably, from 25 to 1 yr. Selected results are sumarized in Fig. 8 . It 

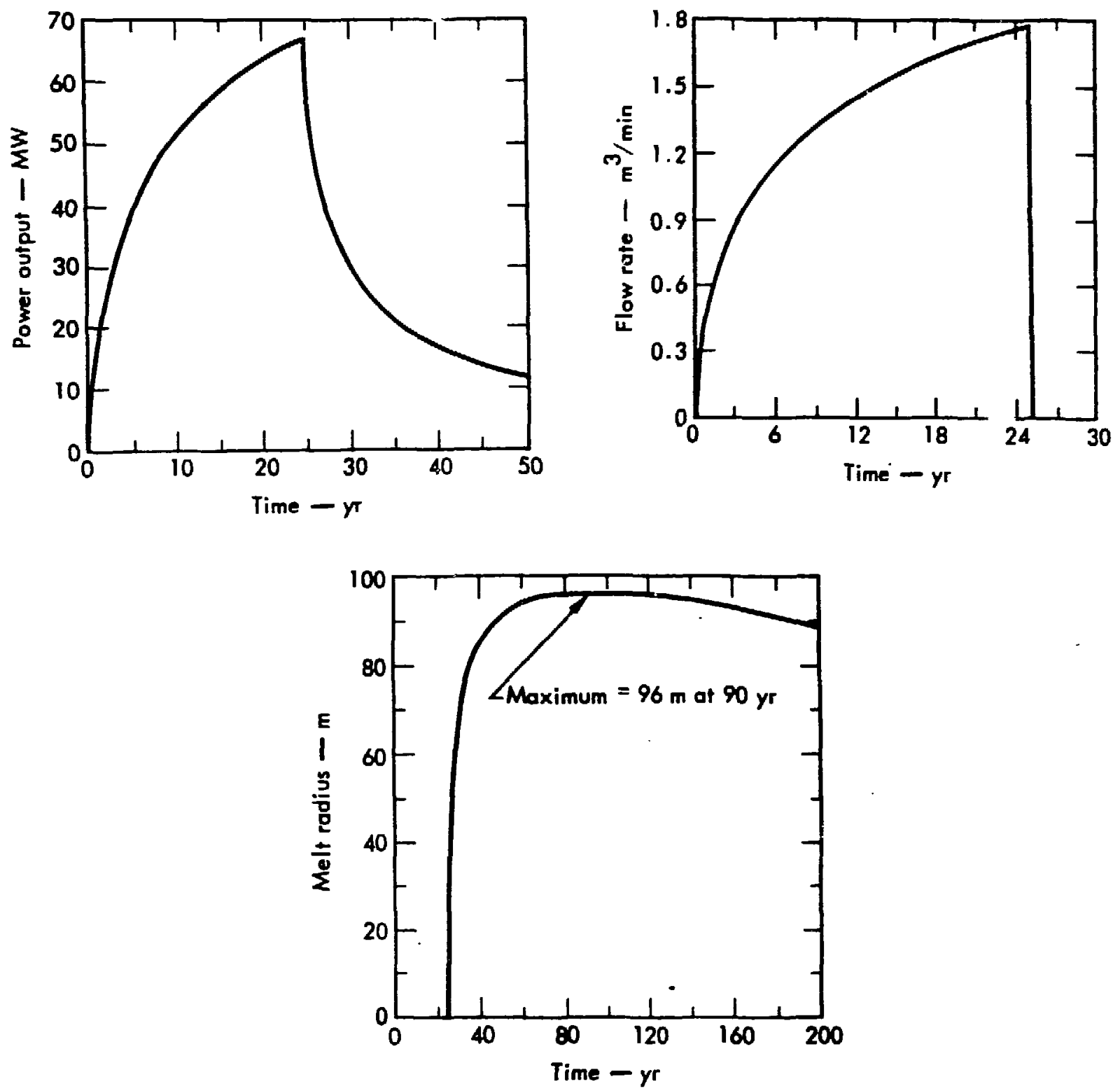

FIG. 7. Results of preliminary thermal calculations for DUMP. 4

is seen that the maximum melt radius is about $80 \mathrm{~m}$ after $60 \mathrm{yr}$. An excess temperature of $250^{\circ} \mathrm{C}$ will persist at a radius of $150 \mathrm{~m}$ for $200 \mathrm{yr}$.

The conductive solution from HEAT did include temperature dependency of $k$ and $c_{p}$. However, it did not allow for convection which is certain to take place in the presence of molten rock. Convective currents will tend to reduce the peak temperatures predicted with a conductive solution. Note that the thermal calculations alone address only one of the four gentechnical questions raised earlier. They do not answer questions about potential releases of radioactive material. 

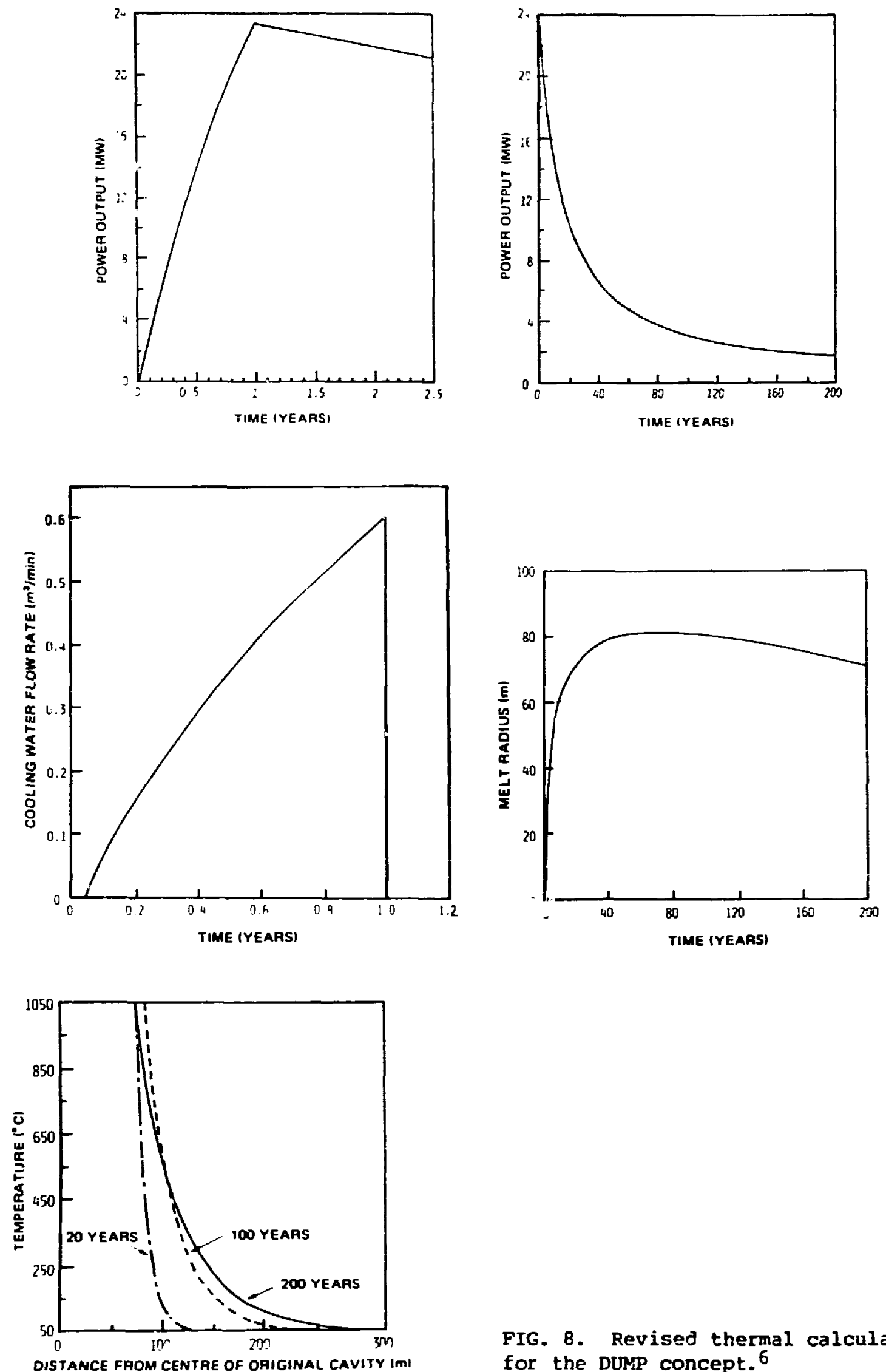

FIG. 8. Revised thermal calculations for the DUMP concept. 6 


\subsection{THE DEEP SELF BURIAL CONCEPT 7,8}

In a first study, ${ }^{7}$ the descent velocity of waste canisters was determined on the basis of an energy exchange, considering the capsule heat output and enthalpy change of rock raised from ambient temperature, through melt, to a temperature required for viscosity reduction. In separate studies on rock melting drills at Los Alamos National Laboratory (UANL), 13-15 it was shown that temperature decays exponentially with distance ahead of a hot penetrating surface, as a function of velocity, and that viscosity ahead of the penetrator has an associated exponential variation. The IANL solution of the Navier-stokes and continuity equations for flow of molten rock from the path of a penetrator was adapted to the case of the waste capsule to determine the differential density between capsule and surrounding rock required to satisfy the hydrodynamic problem; the capsule surface temperat:-e rises until the rock viscosity is low enough to permit the descent velocity associated with the energy exchange and the existing differential density. Descent continues until the thermal power decays to a rock melt threshold value. 7 Sample calculations were performed for disposal in granite, assuning the following properties:

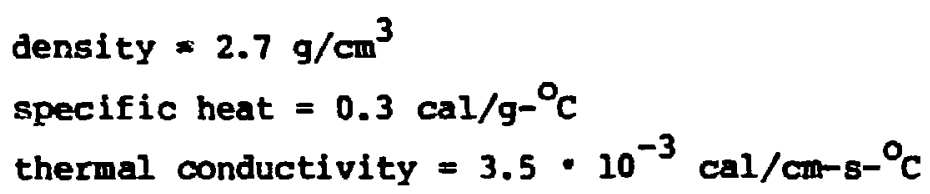

The results are sumarized in Table 1. It is seen that self-burial depths in excess of $10 \mathrm{~km}$ are considered possible with an initial canister surface temperature of $1800^{\circ} \mathrm{C}$. As for the capacity of sush a system, it was stated that each capsule of $50-\mathrm{cm}$ radius and 308 waste concentration accomodates the annual fission product wastes from one 1000-ive nuclear power plant, or Sr + Cs wastes from six plants, or actinide wastes from ten plants. In a separate study, ${ }^{8}$ an approximate solution was obtained for the migration velocity of a spherical source. The results were presented as dimensionless velocity $\mathcal{V}$, versus dimensionless heat rate $D / E$, for different 
TABLE 1. Final depth of burial for waste capsules in granite (adapted from Ref. 7).

\begin{tabular}{|c|c|c|c|c|c|c|c|c|c|}
\hline & & \multicolumn{2}{|c|}{ Capsule } & \multicolumn{4}{|c|}{ Initial conditions } & \multicolumn{2}{|c|}{ Final depth } \\
\hline \multicolumn{2}{|c|}{ Haste } & \multirow{2}{*}{$\begin{array}{l}\text { Radius } \\
\text { (cm) }\end{array}$} & \multirow{2}{*}{$\begin{array}{l}\text { Density } \\
\left(\mathrm{g} / \mathrm{cm}^{3}\right)\end{array}$} & \multirow{2}{*}{$\begin{array}{c}\text { Surface } \\
\text { temperature }\left({ }^{\circ} \mathrm{C}\right)\end{array}$} & \multirow{2}{*}{$\frac{\mathrm{q}^{\prime \prime \prime}}{\left[\mathrm{cal} /\left(\mathrm{cos}^{3} \mathrm{~s} i\right]\right.}$} & \multirow{2}{*}{$\begin{array}{l}\text { Age } \\
(\mathrm{yr})\end{array}$} & \multirow{2}{*}{$\frac{v}{\left(m / d^{\prime}\right.}$} & \multirow{2}{*}{$\begin{array}{l}\text { Age } \\
(y r)\end{array}$} & \multirow[b]{2}{*}{$(\mathrm{k} \pi)$} \\
\hline Type & Fraction & & & & & & & & \\
\hline Fission & 0.15 & 50 & 3.5 & 1800 & 0.08 & 0.6 & 1.9 & 9 & 3.0 \\
\hline \multirow[t]{5}{*}{ products } & 0.30 & 50 & 4.0 & 1800 & 0.09 & 1.1 & 2.1 & 18 & 4.3 \\
\hline & 0.50 & 50 & 4.7 & 1800 & 0.10 & 1.5 & 2.4 & 32 & 6.0 \\
\hline & 0.15 & 100 & 3.5 & 1800 & 0.03 & 1.4 & 1.6 & 36 & 4.6 \\
\hline & 0.30 & 100 & 4.0 & 1800 & 0.04 & 2.5 & 1.8 & 82 & 7.7 \\
\hline & 0.50 & 100 & 4.7 & 1800 & 0.04 & 3.6 & 2.0 & 140 & 11.6 \\
\hline \multirow[t]{6}{*}{ Actinides } & 0.15 & $5 c$ & 4.2 & 1650 & 0.04 & 0.5 & 1.0 & 8.5 & 2.8 \\
\hline & 0.30 & 50 & 5.2 & 1750 . & 0.08 & 0.5 & 1.9 & 23.5 & 4.5 \\
\hline & 0.50 & 50 & 6.8 & $1300^{\circ}$ & 0.19 & 0.6 & 2.9 & $5:$ & 7.3 \\
\hline & 6.15 & 100 & 4.2 & $18 c 0$ & 0.04 & 0.5 & 4.9 & 63 & 5.7 \\
\hline & 0.30 & 100 & 5.2 & 1800 & 0.04 & 1.1 & 2.1 & 200 & 12.2 \\
\hline & 0.50 & 100 & 6.8 & 1800 & 0.05 & 1.9 & 2.4 & .500 & .25 \\
\hline \multirow[t]{6}{*}{$s r+C_{s}$} & 0.15 & 50 & 3.2 & 1800 & 0.07 & 1.5 & 1.6 & 28.5 & 5.3 \\
\hline & 0.30 & 50 & 3.5 & 1800 & 0.08 & 2.8 & 1.9 & 85 & 10.9 \\
\hline & 0.50 & 50 & 3.9 & 1800 & 0.09 & 4.6 & 2.1 & 187 & 19.8 \\
\hline & 0.15 & 100 & 3.2 & 1800 & 0.03 & 3.8 & 1.4 & 155 & 11.6 \\
\hline & 0.30 & 160 & 3.5 & 1800 & 0.04 & 7.3 & 1.7 & $>500$ & $>30$ \\
\hline & 0.50 & 100 & 3.9 & 1800 & 0.04 & 12.5 & 1.8 & $>500$ & $>44$ \\
\hline
\end{tabular}

values of the dimensionless melt parameter E (see Fig. 9). The quantities were defined as follows:

$$
\begin{aligned}
& v=v r_{o} / K \\
& D=3 q C_{p} / 4 \pi k r_{0} L_{,} \text {dimensionless specific heat rate } \\
& E=C_{p}\left(T_{M}-T_{0}\right) / L
\end{aligned}
$$

with $C_{p^{\prime}}, K_{\text {, }} q, T_{M^{\prime}} T_{\circ}, \alpha, K$, defined as in 1.3 and

$$
\begin{aligned}
& r_{0}=\text { radius of spherical source } \\
& v=\text { migration velocity. }
\end{aligned}
$$

Typical values of $E$ for granite would be in the range of 3 to 4 depending upon $T_{0^{*}}$ Good agreement was obtained between these predictions and test results on several materials, with spherical heaters using low porer (Table 2). The migration velocity was quite insensitive to the relative density of the source and the surrounding medium. 


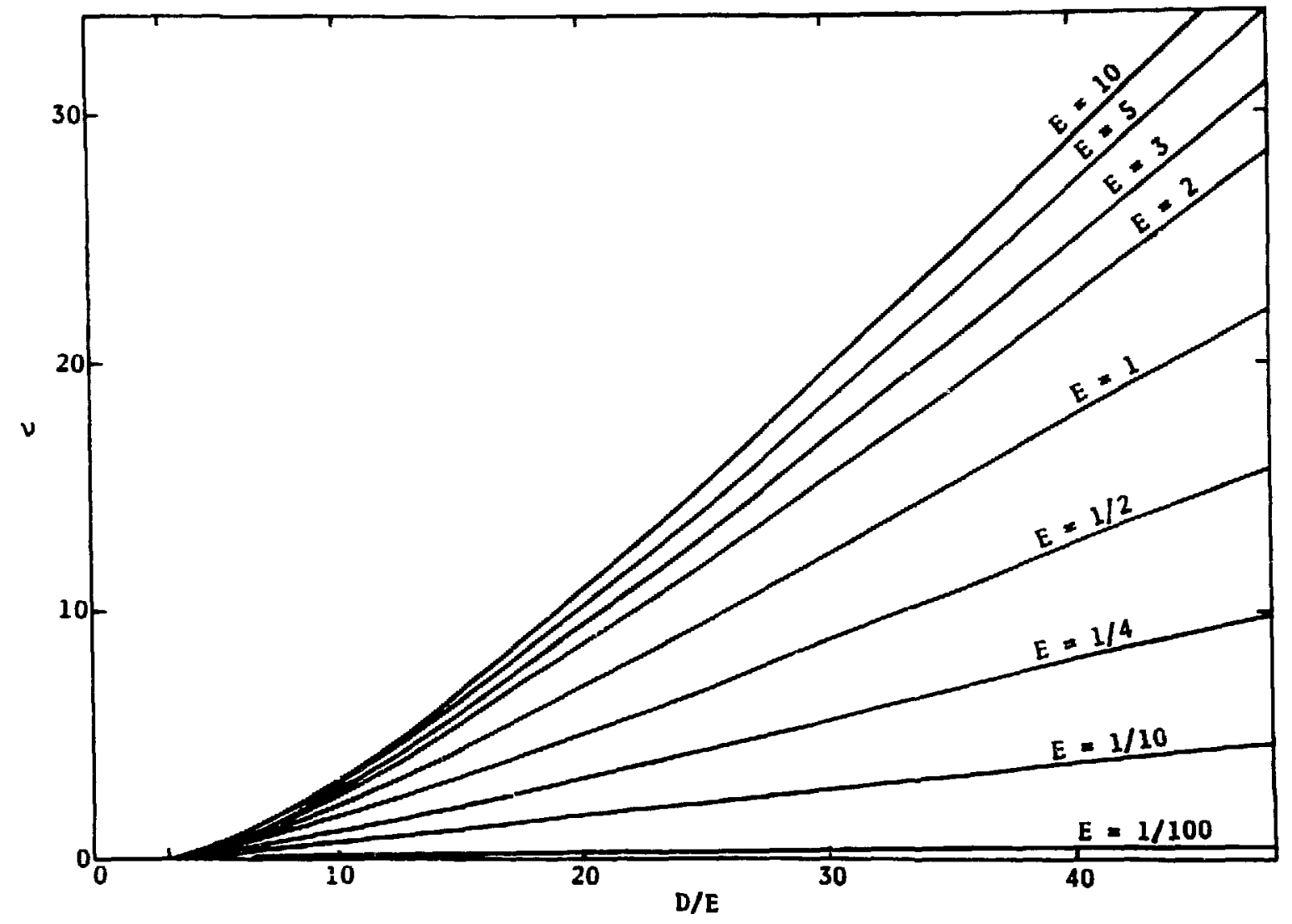

FIG. 9. Dimensionless velocity $(U)$ as a function of dimensionless heat rate $(D / F)$ for varlous $B$ galues.

TNBLE 2. Comparison of actual and theoretical downward migration velocities for various materials at a heat generation rate of $22 \mathrm{w} .^{8}$

\begin{tabular}{lccccc}
\hline Laterial & $\mathrm{D}$ & $\mathrm{B}$ & $\mathrm{D} / \mathrm{B}$ & $v_{\text {theoretical }}$ & $v_{\text {measured }}$ \\
\hline Paraffin & 22 & 0.587 & 37 & 12.7 & 11.0 \\
Beeswax & 122 & 0.664 & 184 & 83.9 & 78.8 \\
Ice & 0.746 & 0.0479 & 15.6 & 0.646 & 0.666 \\
Shortening & 42.3 & 0.277 & 152 & 38.7 & 36.0 \\
& & & & & \\
\hline
\end{tabular}


The above calculations again were hased on conductive heat transfer. However, it seems that convective effects may not be too important in such cases because of the constant downward migration of the heat source. Nevertheless, the containment problem may be quite severe. Canisters would have to keep their integrity at temperatures up to $1800^{\circ} \mathrm{C}$ over the few hundred years required to reach depths of many kilometres. The design of such capsules certainly would not be a trivial affair. The self-burial calculations have been verified only at low power heating and in non-rock materials. 8

The concept, however, appears to have enough merit to justify an initial verification program in real rock at temperatures comparable to those in Table 1. A scaled physical test could be implemented in which a small size capsule could be released in a shallow hole and later recovered. Such a test would be perforned in the laboratory on a granite block of a few cubic metres or in a field test at an active granite facility, such as the Spent Fuel Test area in the Climax granite. 16,17 A numerical model including thermal, mechanical, and creep effects would be verified against the results of the physical test. After verification, the model would be used to recalculate the results of Table 1 to decide whether the self-burial depths previously calculated are realistic.

\subsection{DEEP ROCR DISPOSAL (DRD) CONCEPT}

In support of the DRD concept, Sandia Laboratories performed a heated block test called "the DRD-1 experiment, " 9 of all studies performed on rock melt disposal, this is the only one which provided a real, scaled, physical model. The test involved placing a $1.1 \mathrm{~m}^{3}$ block of dolerite or diabase (a basic Igneous rock) in a pit backfilled with sand. A center hole accomodated an electric heater having a maximum power of $4 \mathrm{~kW}$ (see Fig. 10). The test lasted over 2 months during which time significant rock melting occurred around the heater cavity, simulating the action of high level waste.

A numerical thermal analysis showed that temperatures in the block could be well bracketed by a combination of pure conduction and pure convection calculations (see Fig. 1I). Pure convection was simulated by using very high values for thermal conductivity. During heating, the block was split by tensile cracks (see Fig. 12). Because the block was unconfined, however, this 


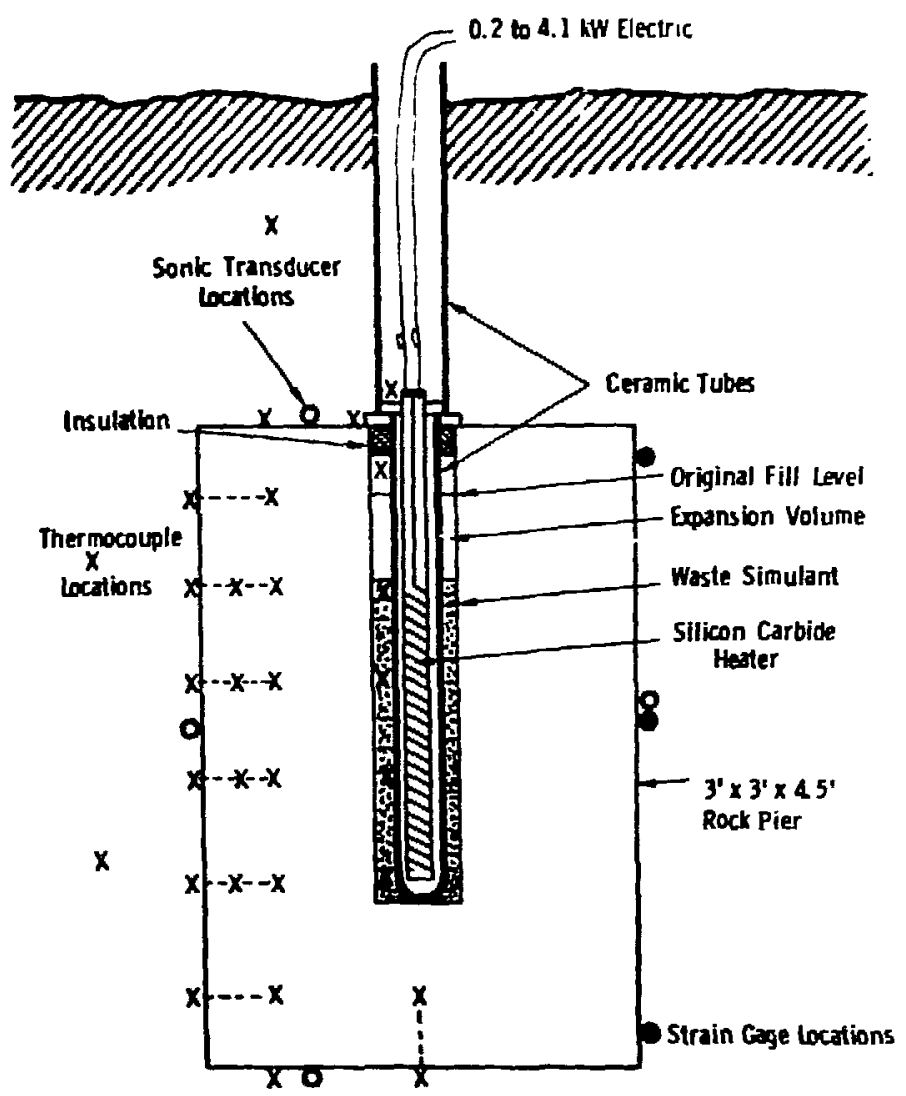

FIG. 10. Schematic of the deep rock disposal block test.9

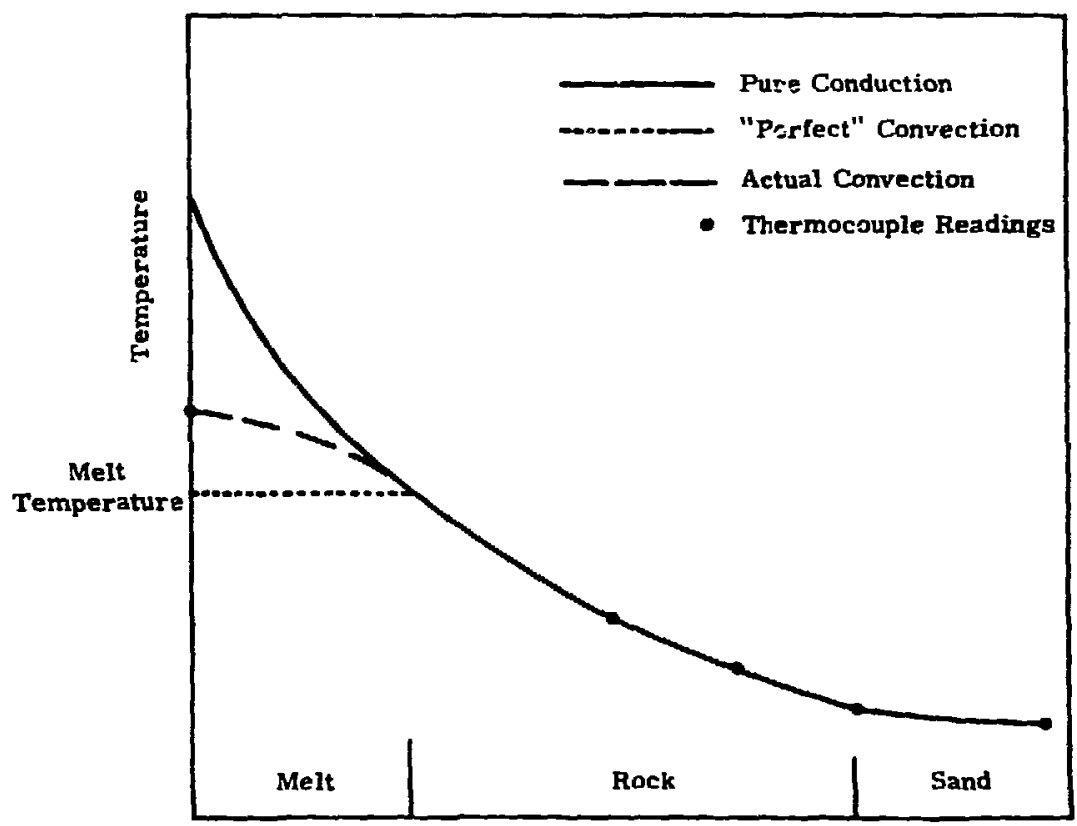

Radial Distance from Heater Tube

FIG. 11. Use of radial thermocouple data.9 


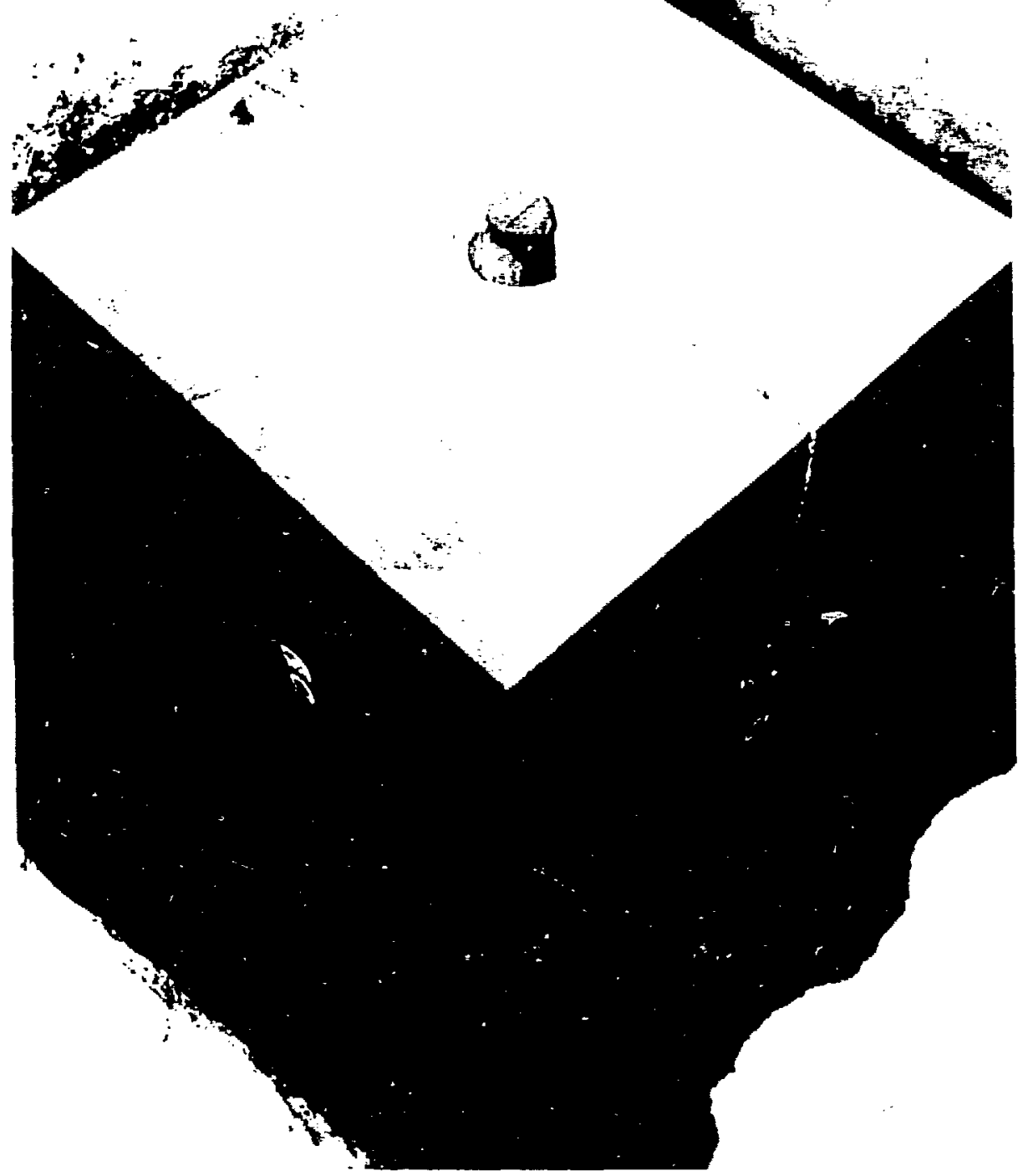

FIG. 12. Uncovered rock showing crack patterns. 9

cracking is not representative of what may happen in a rock mass at depth, under high lateral conflnement. 18 Also, it was found that the rock melt had refrozen before creeping into these cracks. The DRD-1 test results also can be used in the verification program of numerical models. However, the dolerite block is very competent and may not provide a representative volume of jointed granites, at depth in the field. 19 
The scenario show in Figs. 4 and 5 was the object of thermal calculations with both the ASM ${ }^{11}$ and TRUMP ${ }^{20}$ codes. The ASM code assumed adiabatic spherical melting. It neglected heat loss away from the growing molten region by conduction through the solid rock, whereas TRunp did provide for this loss. Neither code modeled free convection in the molten zone. Typical calculations involved an initial cavity with a radius of $5 \mathrm{~m}$. The radius was kept small to minimize peak temperatures in the melt zone. The influence of the initial power loading on the radius of melt for different relative values of conductivity, $k$, is shown in Table 3 . In these TRUMP calculations, the basic $k$ was chosen to have the same temperature dependency as used in the DUMP calculations (see Paragraph 2.1). Figure 13 compares melt radii calculated with ASH and TRUMP for various anounts of total heat input in the cavity. It is seen that the iess refined ASM model predicts larger melt zones, since it does not allow for certain heat losses.

As in all previous calculations only thermal aspects of rock melt disposal were calculated. No studies were made of possible release scenarios, such as rock melt and/or gases reaching aquifers or escaping to the atmosphere.

TABLE 3. Influence of initial power loading on radius of melt.

\begin{tabular}{|c|c|c|c|}
\hline \multirow{3}{*}{$\begin{array}{c}\text { Intial source } \\
\left(\mathrm{H} / \mathrm{m}^{3}\right)\end{array}$} & \multicolumn{3}{|c|}{ Maximum molten radius (m) } \\
\hline & \multirow{2}{*}{$\begin{array}{c}\text { Normal } \\
\text { conductivity }\end{array}$} & \multicolumn{2}{|c|}{ Enhanced conductivity } \\
\hline & & $(\times 10)$ & $(\times 100)$ \\
\hline 1088.2 & 8.0 & 9.0 & 9.0 \\
\hline 870.6 & 7.0 & 8.0 & 8.0 \\
\hline 652.9 & 6.0 & 6.0 & 6.1 \\
\hline 435.3 & 5.0 & 5.0 & 5.0 \\
\hline 217.6 & \multicolumn{3}{|c|}{ - } \\
\hline
\end{tabular}




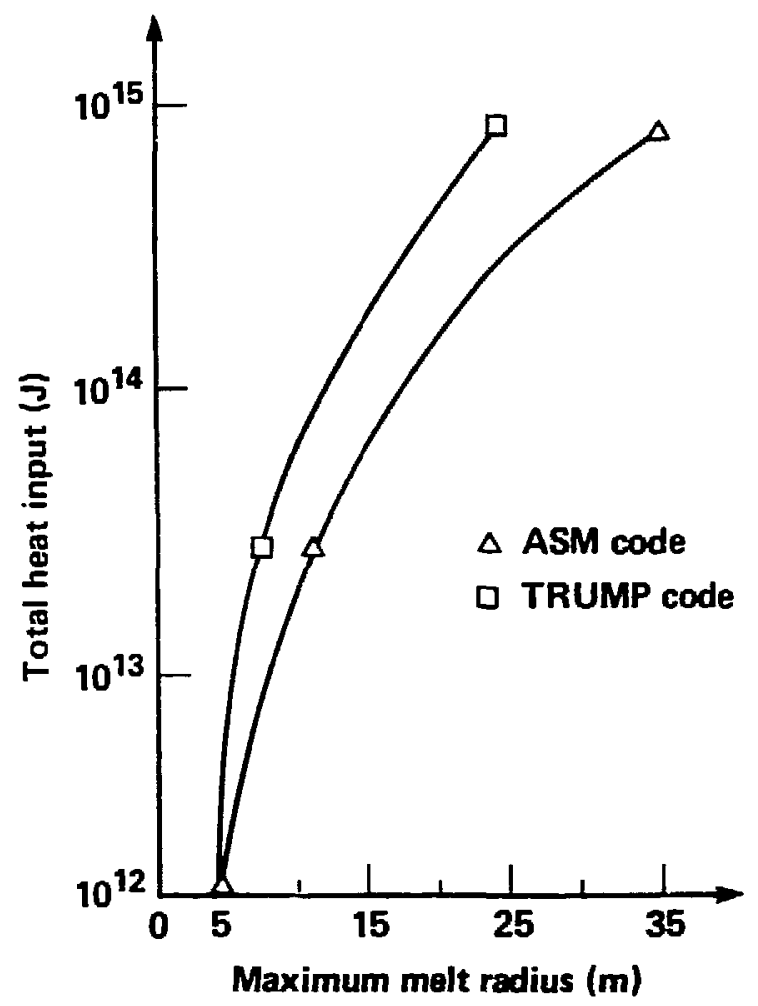

FIG. 13. Calculations of maximum melt radius in the solidifled waste in situ melting concept. 11 
The analysis of any DRM scenarto will require that coaplex coupled phenomena be simulated. It seems that only numerical models can perform such calculations. These models, however, must be verified anong each other if possible, and calibrated against scaled physical experiments such as the rock block tests discussed earlier. Analytical solutions ${ }^{21-26}$ also can provide a measure of verification, but they can be applied only to the simplest forms of analysis, usually involving homogeneity, isotropy, and linearity.

In the next paragraphs we establish the desirable features of the models, we review computer programs which possibly can be applied to DRY analysis, and we attempt to outline a modeling strategy, using the best features of selected codes.

\subsection{DESIRABLE FEATURES OF MODELS}

- The complexity of the thermal/mechanical/hydraulic analyses would Indicate that finite difference (FD) ox finite element (FE) models shouid be used. Boundary methods have not reached a sufficient level of sophistication to be considered at this time.

- The geometry of most scenarios is cylindrical or spherical. Fracture propagation under internal pressure could be analyzed as planar. Hence it seems that two-dimensional models, both plane and axisymetric, would be adequate in a first stage.

- The structural mechanics aspects of DRM require that the elastic response as well as the creep be modeled. In addition, fracture mechanics capabilities should be available for DRM analyses.

- Free convection will play a large role in the heat transfer; thus, the thermo-mechanical solutions must be strongly coupled.

- The slow viscous motion of rock over long periods of time seems to require implicit numerical solutions to satisfy computational stability within reasonable computing time.

- Viscous dissipation should be included to determine if it is a significant component of the thermo-mechanics of DRH.

- Mechanical and thermal properties of the DRM systems will be strongly temperature dependent. In particular, sharp variations in several material properties during melting and solidification require that curve description types of input to the codes be available. 
- The models must accomodate large deformations of the rock mass and large displacements of components such as the canisters in the self burial scenario. Rezoning of Lagrangian meshes may be required. Also, the algorithms in the codes must provide for a stress increnent which is invariant to rigid rotations.

- Cracks may be driven in the rock mass by gases and vapor. Rock melt with a free surface may also propagate in rock fractures. For such flow problems, the use of Eulerian models seems preferable to that of Lagrangian formulations.

- The availability of pre- and post-processors certainly would be a very desirable feature of any candidate computer program and would make the handling of input and output data more efficient.

\subsection{POTENTIAL CANDIDATE COMPUTER PROGRAMS}

An extensive literature search was performed which touched upon numerous subjects. Some of the topics considered were nongeological, but all had some relevance to the mechanics of the DRM problem. Because of the considerable breadth of developments in FE and FD models, such a search certainly was not exhaustive; however, it should give a good representation of relevant capabilities of existing codes. The overall survey is arbitrarily summarized under the fo'lowing headings:

- General purpose mechanical, thermal and hydraulic codes in geomechanics and structural mechanics. 12, 27-33

- Geomechanics of conventional nuclear waste disposal in mined underground cavities. 34-36

- Fluid flow in fractured rocks, including models of geothermal reservoirs. $37-41$

- Discrete fracture propagation in rock under tensile and shear stresses, 42 under thermal loading, 43 and under internal pressure. $44-47$

- Incompressible flow with thermally driven convection. 48-50

- Heat transfer problem with melting and solidification. 51-54

- Viscous creep in the earth's crust, ${ }^{55-68}$ as in folding, magmatic intrusions, diapirism, and plate tectonics.

- Migration of waste canisters in ocean sediments. 69,70 
Based on the criteria previously listed, six codes were retained. Their main features are sumarized in Table 4 and its footnotes. The codes fall into two categories. The first three, SANGRE, COUPLEFLO, and KRAR appear to be readily applicable to DRM modeling. The last three, NACHOS, TACO/NIKB-2D, and ADINA/ADINAT would require modifications and general enhancement. Still, they are listed because of their general capabilities and availability. The main qualities and linitations of the first three programs are:

- SANGRE 55,63 : The code has been used successfully to model strongly coupled viscous thermal creep problems. It is readily available from LANL and adaptable to the LLNL system. On the other hand, it is Lagrangian and may require rezoning if large mesh distortions are experienced. It does not provide for fracture mechanics or for a time-dependent input of heat source. This last capability probably can be added without excessive cost.

- COUPLEFLo65,66: The Eulerian thermo-mechanical coupled capability of the code would make it very attractive to study canister migration in a self burial concept. On the other hand, its main drawback is the fact that it models only creep. For example, in the Dunp concept it would not be applicable because it would not give the stress distribution in the nonmelted, solid rock.

- $\operatorname{KRAR}^{47}$ : The code has been used to model gas contaimment problems related to nuclear explosions, and it has fracture mechanics capabilities. It can be obtained from IANL. On the other hand, the code doss not have solid mechanics capabilities.

The main limitations of the second series of codes are:

- MACEOS ${ }^{49,50}$ : The code cannot model more than one material and cannot show a canister descending through molten rock. It would require some enhancement, such as temperature-dependent density, to model a convective molten rock magma in a solid rock mass. It does not provide for free surfaces and does not have viscous aissipation. - IACO/NIRB-20 31,33 : The code is uncoupled. It does not model creep or convection.

- ADINA/ADINaT28,29: The code is uncoupled. It does not have a Weertman or equivalent creep model and does not model convection. 
TABLE 4. Summary of capabilities for the candidate codes to model DRM thermo-mechanics and thermo-hydraulics.

\begin{tabular}{|c|c|c|c|c|c|c|}
\hline & SANGRE & CODPLEFLO" & KRAR * & NACHOS $^{\dagger}$ & ${ }_{\text {NIKE-2D }}^{\dagger}$ & $\begin{array}{l}\text { ADINA/ } \\
\text { ADINAT }\end{array}$ \\
\hline $\begin{array}{l}\text { Finite elements } \\
\text { Finite differences }\end{array}$ & $\mathrm{x}$ & $x$ & $\mathbf{x}$ & $x$ & $\mathrm{x}$ & $x$ \\
\hline Plane & $x$ & $x$ & & $\mathrm{x}$ & $x$ & $\mathbf{x}$ \\
\hline Axisymmetric & $x$ & $x$ & $x$ & $\mathrm{x}$ & $x$ & $x$ \\
\hline Lagrange & $\mathrm{x}$ & $\mathrm{x}^{\mathrm{a}}$ & $x$ & & $\mathrm{x}$ & $\mathrm{x}$ \\
\hline Euler & & $\mathbf{x}$ & $\mathrm{x}$ & $\mathrm{x}$ & & \\
\hline Transient & $\mathrm{x}$ & $\mathrm{x}$ & $\mathrm{x}$ & $\mathrm{x}$ & $x$ & $\mathrm{x}$ \\
\hline Implicit & $x$ & $x$ & $\mathbf{x}^{\mathbf{b}}$ & $\mathbf{x}$ & $x$ & $\mathrm{x}$ \\
\hline Coupled & $x$ & & & & $\mathrm{x}$ & $\mathbf{x}$ \\
\hline Elastic solids & $x$ & & & & $x$ & $\mathrm{x}$ \\
\hline Fracture mechar:ic: & & & $\mathrm{x}$ & & & \\
\hline Weertman creepc & $\mathrm{x}$ & $\mathrm{x}$ & & & & \\
\hline Meltingd & $\mathrm{x}$ & $x$ & & & $\mathbf{x}$ & $x$ \\
\hline Incompressible & $\mathrm{x}$ & $\mathrm{x}$ & & $\mathbf{x}$ & & $\mathrm{x}$ \\
\hline Convection & $x$ & $x$ & & $\mathrm{x}$ & & \\
\hline Newtonian & $\mathrm{x}$ & $\mathrm{x}$ & $\mathbf{x}$ & $\mathrm{x}$ & & \\
\hline viscous dissipation & $\mathrm{x}$ & $x$ & & & & \\
\hline Free surface & $\mathrm{x}$ & $\mathrm{x}$ & & & & \\
\hline Time-dep. heat source & & $x$ & $\mathbf{x}$ & $\mathrm{x}$ & & $\mathrm{x}$ \\
\hline Multi-material & $\mathrm{x}$ & $x$ & $\mathbf{x}$ & & $x$ & $x$ \\
\hline Anisotropy & $\mathrm{x}$ & $\mathrm{x}$ & & & $\mathbf{x}$ & $\mathbf{x}$ \\
\hline Temp.-dep. properties & $\mathrm{x}$ & $x$ & $\mathrm{x}$ & $\mathbf{x}$ & $\mathrm{x}$ & $\mathbf{x}$ \\
\hline Pre-post-processor & $\mathbf{x}$ & $\mathbf{x}$ & & $\mathbf{x}$ & $\mathbf{x}$ & $\mathbf{x}$ \\
\hline Origin & LAML & SANDIA & IANL & IANL & LLNL & MIT \\
\hline Remarks & * $T$ & $\begin{array}{l}\text { e codes are } \\
\text { ily usable. }\end{array}$ & & $\begin{array}{c}\text { t Thes } \\
\text { with } \\
\text { enha }\end{array}$ & $\begin{array}{l}\text { e codes ar } \\
\text { modificat } \\
\text { ncement. }\end{array}$ & $\begin{array}{l}\text { e usable } \\
\text { ions and }\end{array}$ \\
\hline
\end{tabular}

a Pseudo-Lagrangian: new system geometry advanced through Euler integration of the velocity field.

b In KRAR, the crack flow and crack propagation are solved implicitly, whereas the porous medium flow is solved explicitly.

C Weertman's law has been adopted by several experimentalists and modelers to describe the steady-state creep of rocks. The relationship between effective strain rate and deviator stress is presented as:

$$
\dot{\varepsilon}=A \cdot \sigma^{n} \cdot \exp (Q / R T)=\sigma \mu .
$$

The inverse viscosity, $\mu$, may be a function of stress and temperature (non-Newtonian flow) or of temperature only (Newtonian flow). A is a material constant, $R$ is the gas constant, $T$ is the absolute temperature, and $Q$ is the creep activation energy which can be determined empirically as proportional to the slope of a plot of $\log \dot{\varepsilon}$ versus $1 / T$ at constant $\sigma$. For most materials, Q remains constant at temperatures between $0.5 \mathrm{Tm}$ and $\mathrm{Tm}$, where $\mathrm{Tm}$ is the melting temperature.

d Programs will be said to handle melting if they can accommodate the related variations in thermal and mechanical properties as well as handle latint heat. Commonly, latent heat is accommodated by using a large increase in heat capacity over a narrow temperature range near melting. 51-54 
Because no single code can model all the geotechnical aspects of DRH (solids, fluids, fractures, ...), we will decompose the problem so that the analysis can be performed in parts, using the best features of various codes. This matching of program capabilities versus physical phenomena leads to proposing that three codes (SANGRE, COUPLEFLO, and KRAR) be applied to four separate analyses which may be recombined to assist in evaluating the various rock melt scenarios discussed in Section 1.2. The proposed models are:

- Cavity melt (Fig. 14): The SANGRE code will be used to obtain the time history of temperatures and rock mass response (stresses and strains), from initial cavity loading to resolidification of the magma. Of particular interest will be the pressure on the surrounding materials created by expansion of the melting rock. $T_{t} s$ will be used to estimate the possibility of cracking the rock formations. Also, the melt pressure would be used as a boundary condition for melt migration in cracks. This analysis will be applicable to the DUMP, Deep Rock Disposal, and In Situ Melting Concepts.

- Melt migration in cracks (Fig. 15): The RRAR code will be used to estimate the possible propagation of rock melt into new cracks or into open fractures. The driving force will be the magma pressure calculated in the cavity melt analysis. Heat exchange will take place with the surrounding medium and the melt viscosity will be strongly temperature dependent. This analysis will apply to the same concepts as the cavity melt analysis.

- Gas and/or vapor migration in cracks (Fig. 15): Water present in the granite would be vaporized in a large zone and the vapor could migrate in cracks; the RRAR code again will be applied. The pressure function driving the cracks is not provided by SANGRE. It will have to be determined by an independent study yet to be defined. The basic idea is to determine how far away from the waste the vapor may migrate before condensing. In that sense, the thermal field defined by SANGRE will be very useful.

- Self-burial analysis (Fig. 16): CODPLEFLo will be applied to predicting canister migration if the ccde can be obtained from SANDIA. The Eulerian formulation, the conduction-convection solution, 


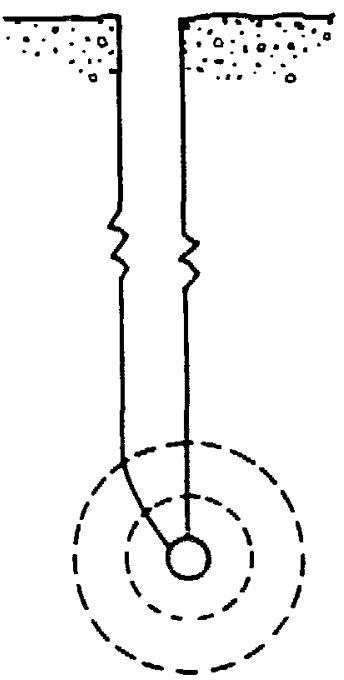

Plowshare

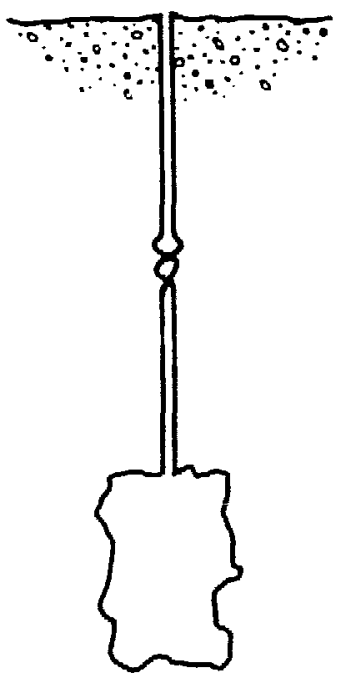

Deep rock disposal

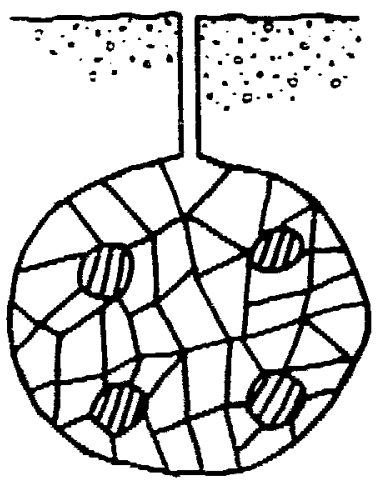

Solidified waste In Situ melting

FIG. 14. Cavity melt scenarios to be analyzed with SANGRE.
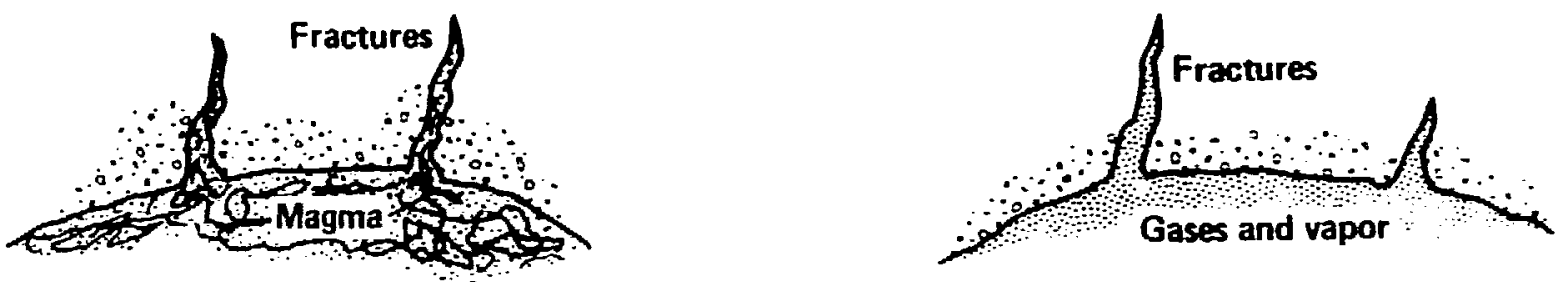

FIG. 15. Melt and vapor migration to be analyzed with GRAR.
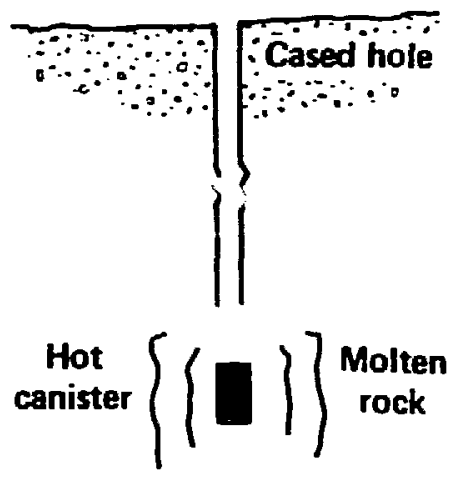

FIG. 16. Deep self burial to be analyzed with COUPLEFLo.

26 
and the coupled creep capability make this code the best candidate for such an analysis.

The matrix relationship between the four analyses, the four acenarios, and the three codes is illustrated in Table 5 .

TABLE 5: Matrix relationship between rock melt scenario, types of analysis, and candidate codes.

\section{Rock melting scenario}

TYpes of analysis

Deep self- Deep rock In situ

and code used

DURP

burial

disposal melting

-Cavity melt/SANGRE

cracks/RRAR

$\mathbf{x}$

$\mathbf{x}$

$\mathbf{x}$

Gas migration in

- cracks/RRAR

$\mathbf{x}$

$\mathbf{x}$

$\mathbf{x}$

Self burial/COUPLEFLO

$\mathbf{x}$

- Strong coupling: SANGRE output defines KRAR input for pressure driving the melt.

Partial coupling: SANGRE output provides temperatures in the solid medium but not vapor pressures for KRAR input. 


\section{ROCK PROPERTIES}

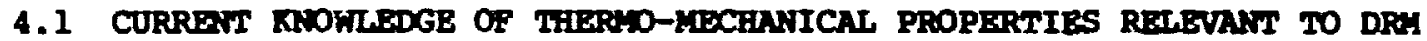

Prior to exercising any model of DRM, one must ascertain that properties used as input to the calculations are known with a reasonable degree of confidence. A comprehensive survey of relevant granite properties over a wide range of temperature and pressure is summarized in this section.

\subsubsection{Modulus}

Results obtained on numerous granites $9,71-76$ are presented in a normalized form, where $\mathrm{E}_{0}$ is the modulus at room temperature, irrespective of pressure. The $\mathrm{E} / \mathrm{E}_{\mathrm{o}}$ variation is shown in Fig. 17 as a function of temperature only. Results obtained with varying temperature and pressure are presented in Fig. 18. Most of the results were obtained on dry materials. Figure 19 shows the envelope of all results and a proposed pressure independent law for the modulus of dry granite.

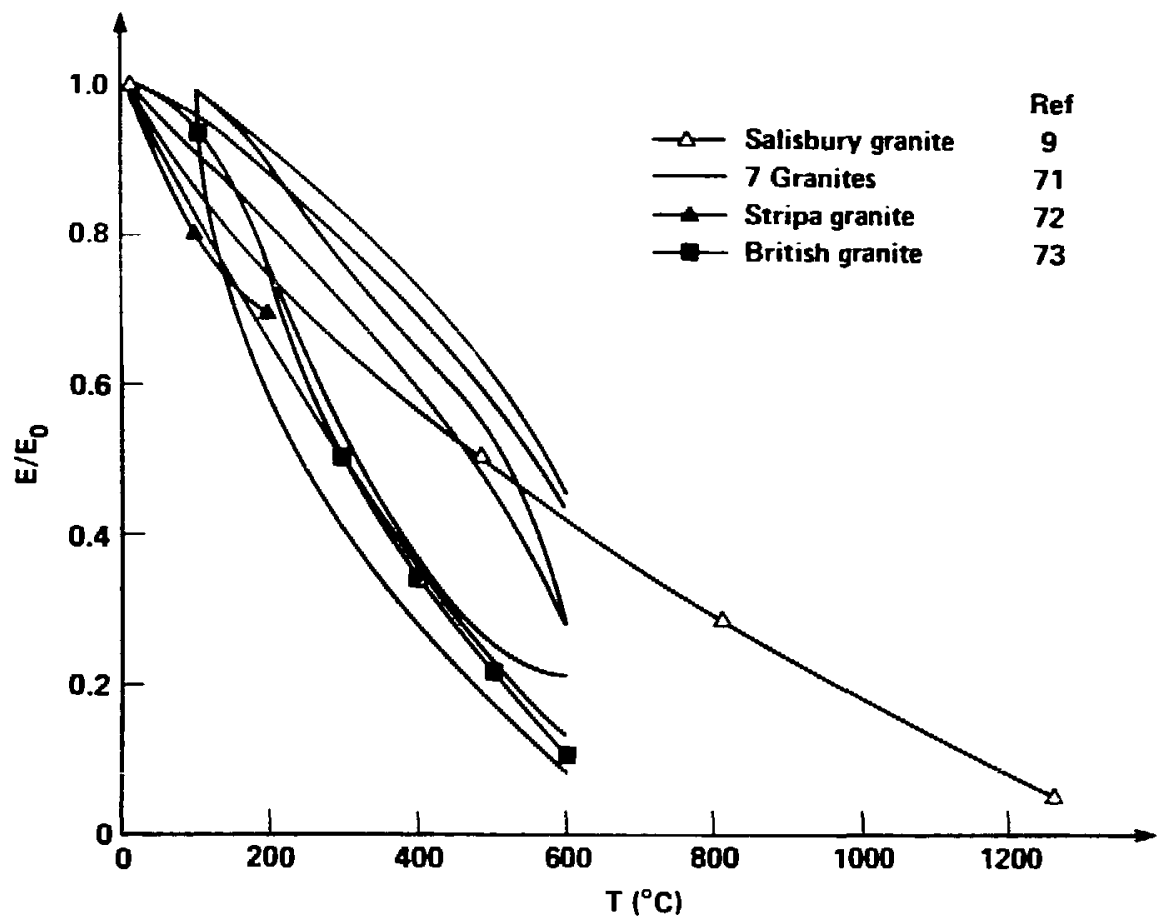

FIG. 17. Normalized modulus versus temperature at atmospheric pressure for several granites. 


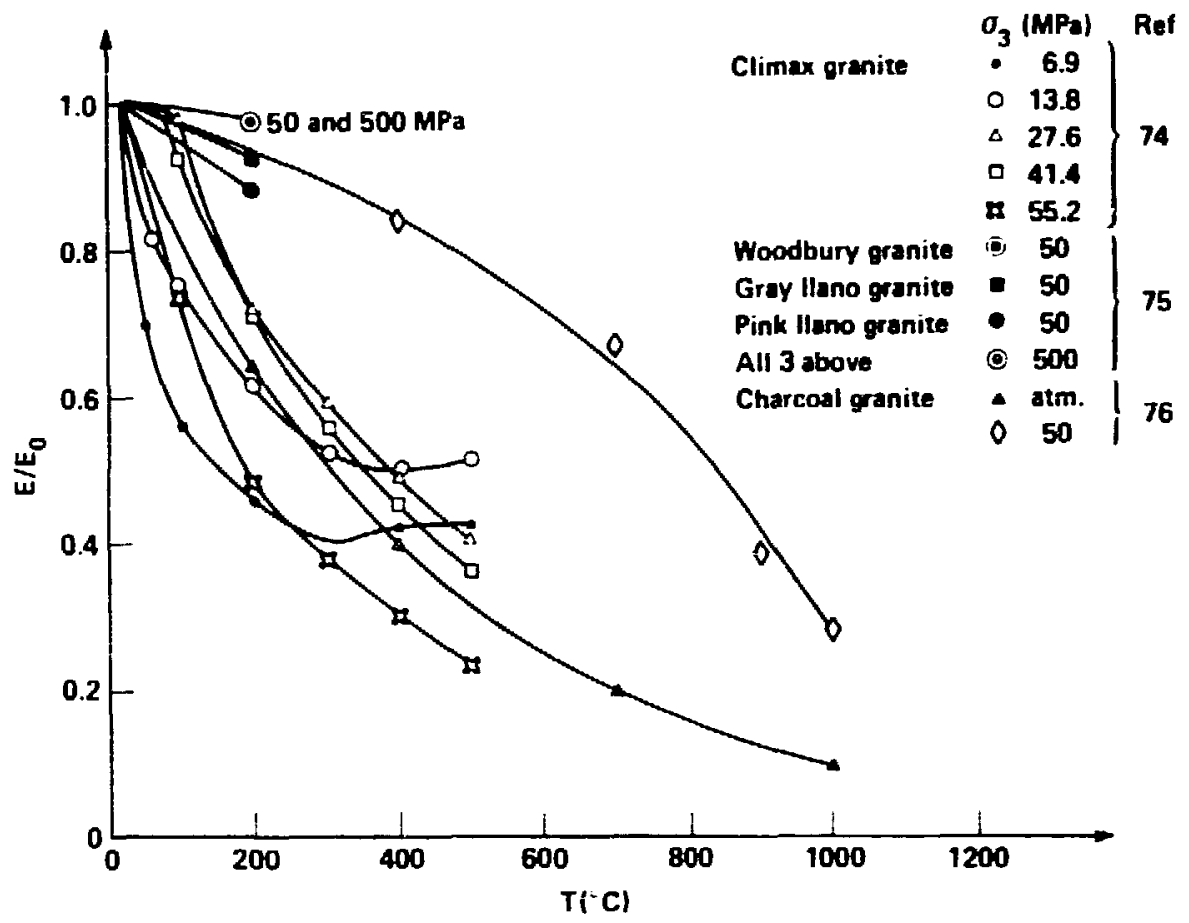

FIG. 18. Normalized modulus versus temperature as influenced by pressure for several granites.

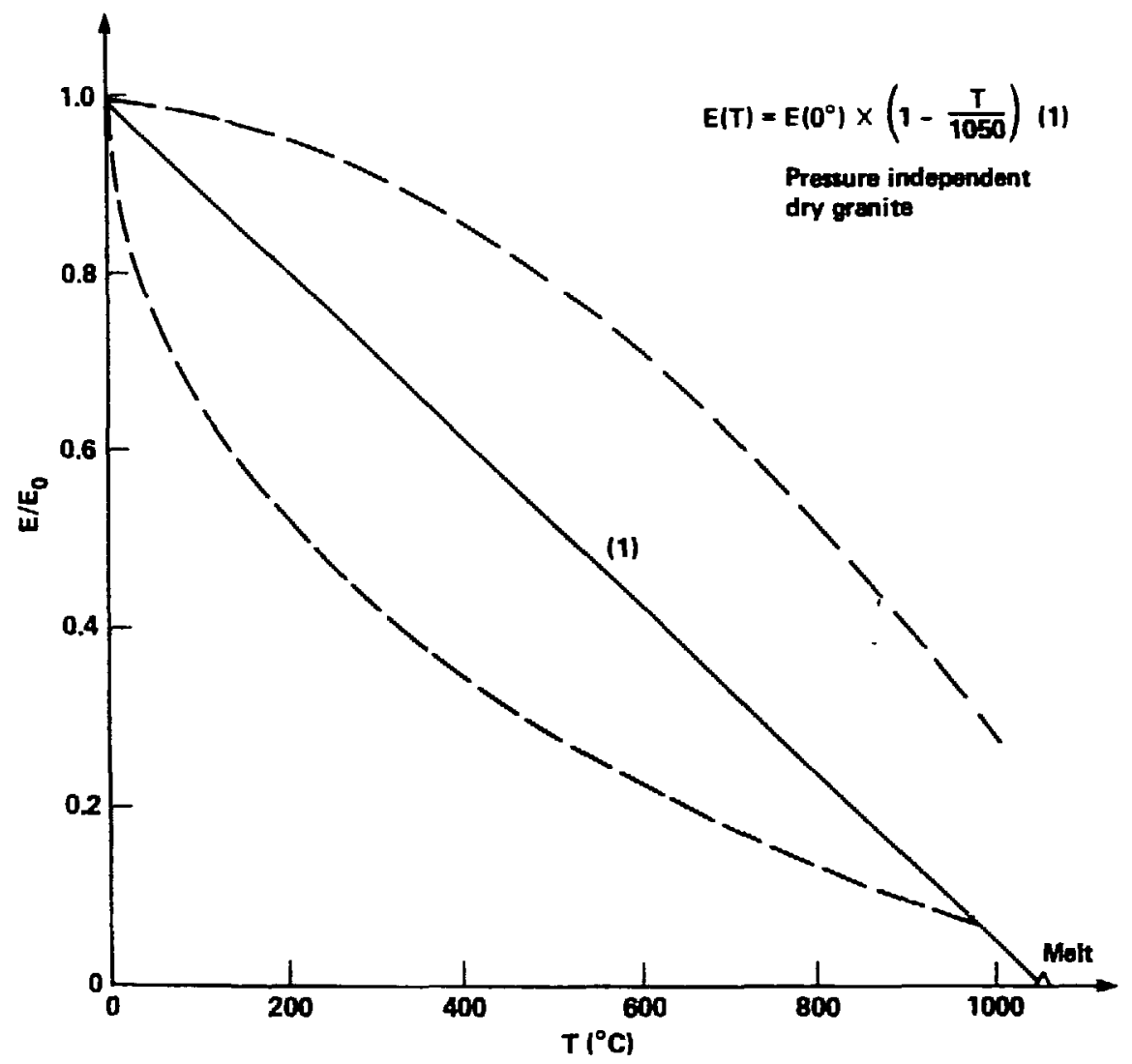

FIG. 19. A possible pressure independent law for the normalized modulus of granite as a function of temperature. 


\subsubsection{Poisson's Ratio}

With stripa granite, 72 v decreased from 0.21 at $20^{\circ} \mathrm{C}$ to 0.13 at $200^{\circ} \mathrm{C}$. Tests on Climax granite ${ }^{74}$ did not show a clear dependence of $v$, either on pressure or on temperature.

\subsubsection{Tensile Strength}

Results for Westerly and charcoal granites ${ }^{76}$ are show in Fig. 20. These were obtained in short-term tests. In long-term loading under very low strain rates $\left(10^{-6} / \mathrm{s}\right)$, the tensile strength may be affected by stress-corrosion cracking. 77

\subsubsection{Compressive Strength}

Comprehensive triaxial compression results have been published for ary Westerly granite 78,79 at temperatures from 23 to $900^{\circ} \mathrm{C}$. The strength envelopes are shown in Fig. 21. These data were used to obtain the variation

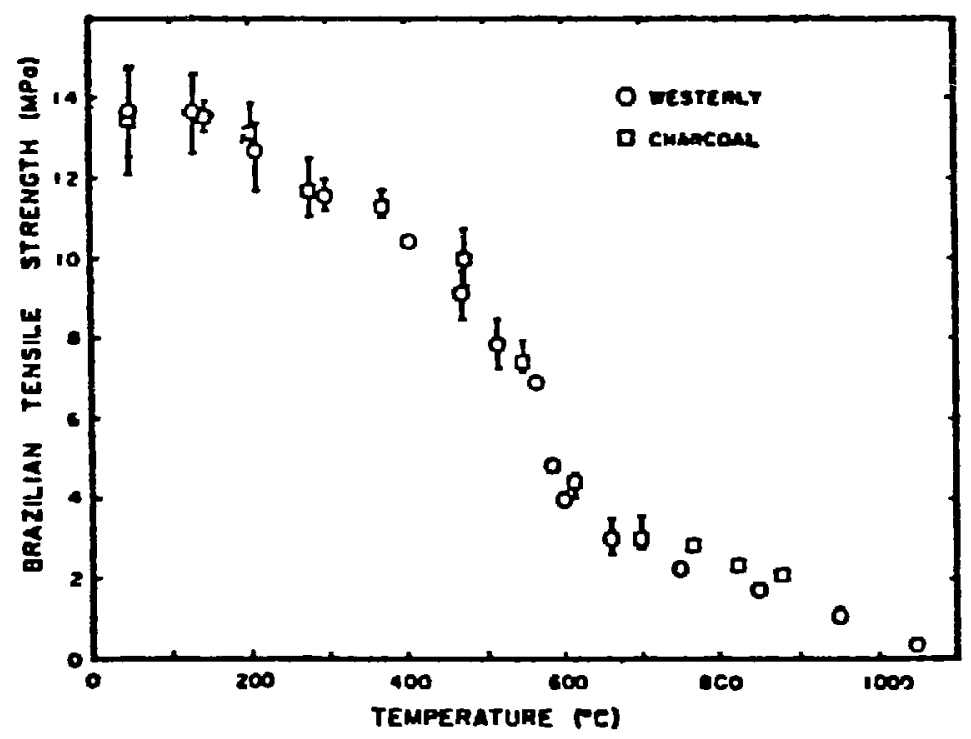

FIG. 20. Tensile strength of granites versus temper ature. 76 


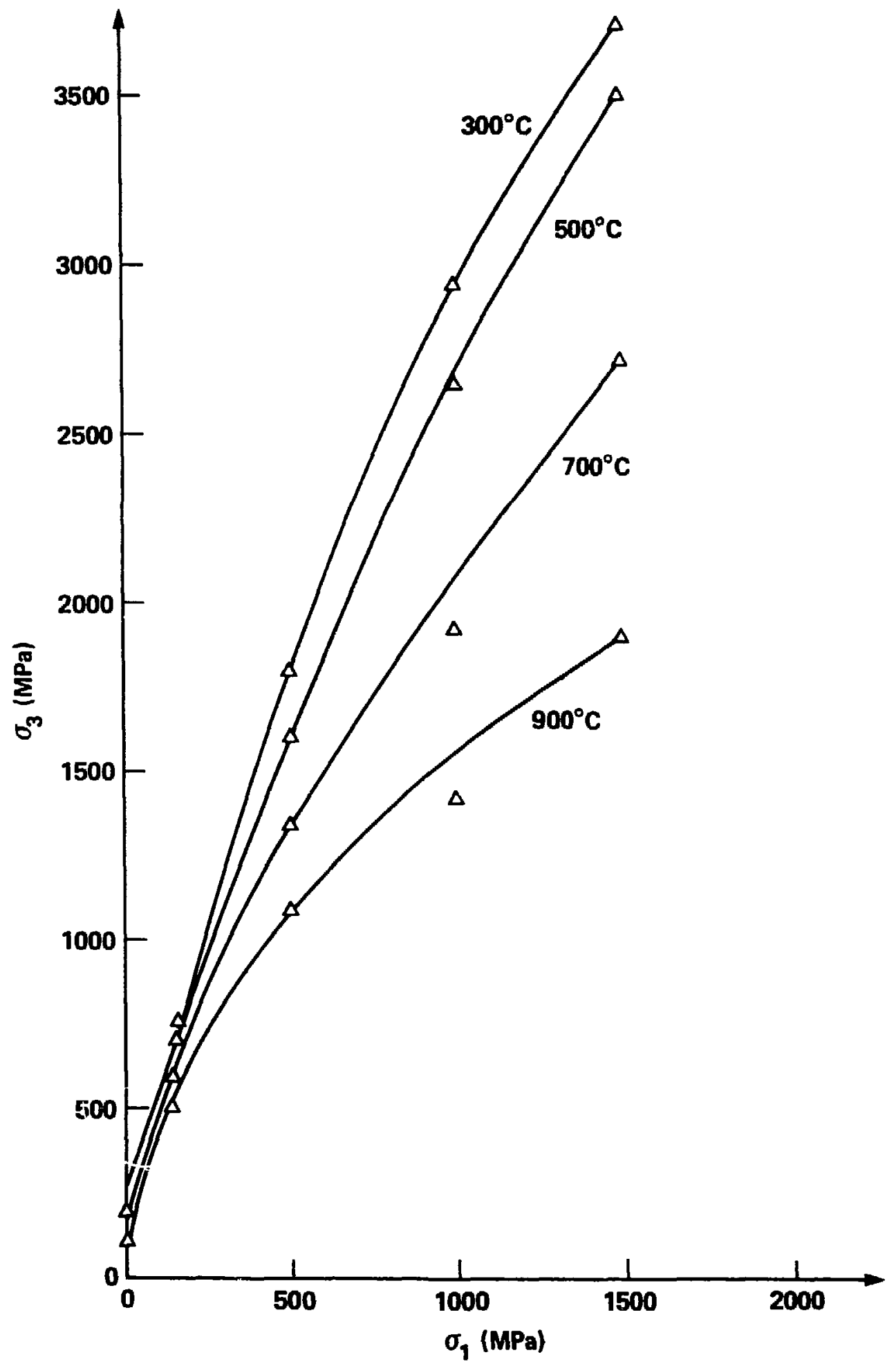

FIG. 21. U1timate strength versus confinement for $d r_{Y}$ weateriy granite as a function of temperature. 78,79 
of friction and cohesion with temperature in dimensionless form (Figs. 22 and 23). The decrease of friction shown in Fig. 23 seems at odds with the results of another study ${ }^{80}$ which stated that frictional stress is unaffected by temperatures up to $300^{\circ} \mathrm{C}$ for Festerly granite saw cuts and $600^{\circ} \mathrm{C}$ for Westerly granite faults. In that same study, it was concluded that with temperatures up to $265^{\circ} \mathrm{C}$, water had $1 i$ :tle effect on the behavior of faulted Westerly granite at $300 \mathrm{MPa}$ effective pressure. This is consistent with results obtained to $1000^{\circ} \mathrm{C}$ on dry and wet charcoal granodiorite, ${ }^{81}$ which showed the wet rock to be slightly stronger than the ary material. Such results may seem to run contrary to the notion of stress-corrosion cracking of rock materials, as enhanced by water and temperature. 82 Here again, however, such phenomena would become apparent only in very long term tests where the strain rates are much lower than those of the above tests. Results obtained on four other granites, $81,83,84$ are summarized in Fig. 24. The ultimate strength can be extrapolated to zero at the melting temperature. The final strength decrease during melting can be precipitous. A granite under $300 \mathrm{MPa}$ confining pressure showed the following decrease in ultimate strength with melt fraction ${ }^{85}$ :

$\begin{array}{rr}58 \text { melt } & 250 \mathrm{MPa} \\ 158 \text { melt } & 60 \mathrm{MPa} \\ 248 \text { melt } & 1 \mathrm{MPa}\end{array}$

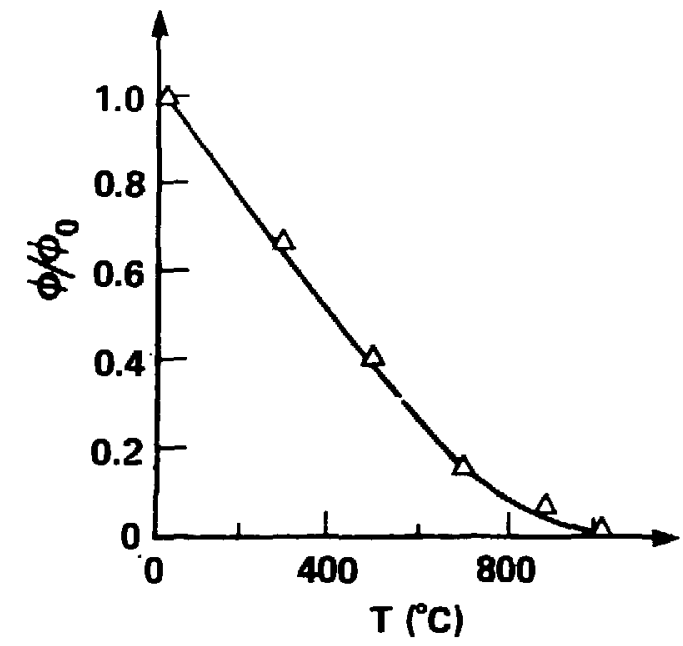

FIG. 22. Dimensionless cohesion versus temperature, obtained from the results of Fig. 21.

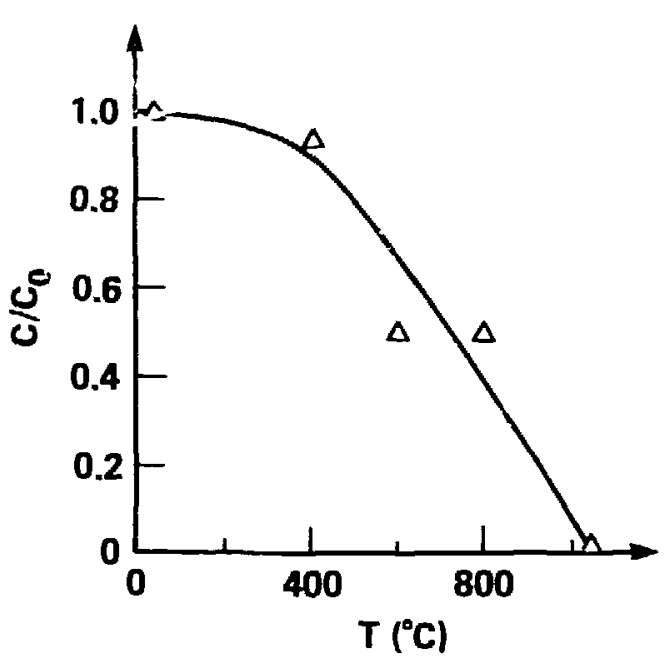

FIG. 23. Dimensionless friction versus temperature, obtained from the results of Fig. 21 . 


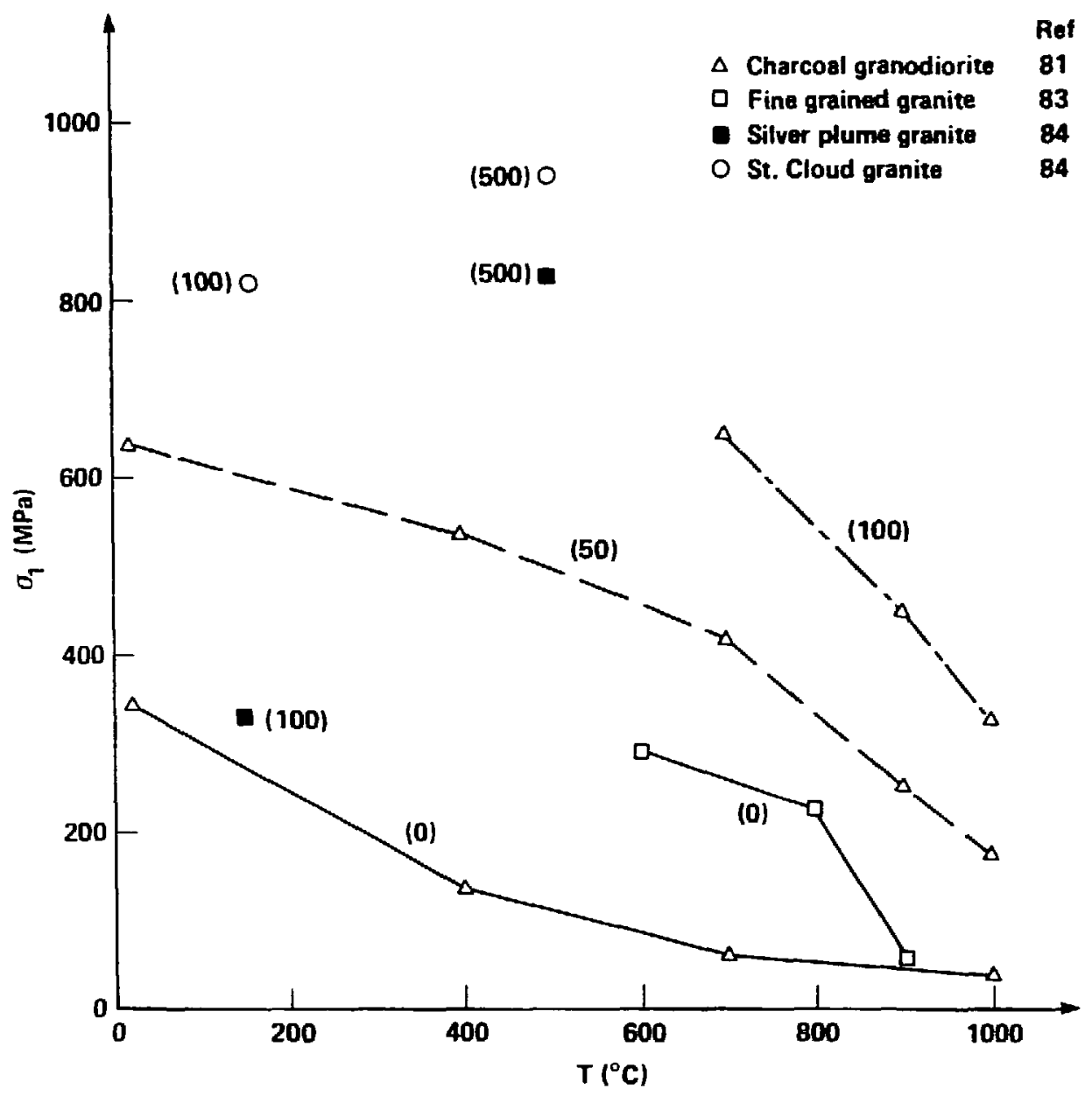

FIG. 24. Ultimate strength versus temperature for various granites (number in brackets show confinement in MPa).

All the above results are for intact rock materials. Because of scale effects due to the presence of joints and faults, the absolute deformability and strength of the rock mass are expected to be lower than the above data. 19 On the other hand, their celative variation with temperature may show a similar functional relationship as that for the small rock volumes. Today, we can only speculate on this matter because of the woeful lack of mechanical data for large rock volumes over the temperature range considered in this study.

\subsubsection{Permeability}

The granite mass permeability has two components: one from the solid material and one from the fractures (joints). Results for the intact material 
are somewhat ambiguous. On one hand, porosity measurements of Climax granite, up to $500^{\circ} \mathrm{C}$, were used to calculate an estimated permeability ${ }^{74}$; $\mathrm{K}$ was predicted to increase with temperature. On the other hand, percolation tests in westerly granite, up to $400^{\circ} \mathrm{C}$, showed a strong decrease in $\mathrm{K}$ due to precipitation taking place during the period between a half day and several days. 86 As for the granite mass as a whole, thermal expansion will tend to close the existing joints, thus reducing the overall permeability. 87 A ten-fold decrease was observed in situ, in the Idaho Springs granite gneiss, for a mere $32^{\circ} \mathrm{C}$ increase in temperature, from 41 to $73^{\circ} \mathrm{C}$. A four-fold decrease was observed in situ, in the stripa granite, for a $25^{\circ} \mathrm{C}$ increase in temperature. 88 In fact, as the granite creeps and closes its fractures at temperatures of several hundred degrees $C$, the permeability probably will drop to levels equivalent to transport by grain boundary diffusion. This is estimated to be at most 1 nanodarcy. 89

\subsubsection{Thermal Expansion}

The variation of the linear thermal expansion coefficient, $\alpha$, with temperature, at atmospheric pressure, is shown in Fig. 25 for numerous granites. 71,90-96 These data, obtained under $500^{\circ} \mathrm{C}$, fall short of the $\alpha$ - $\beta$-transition of quart? $\left(573^{\circ} \mathrm{C}\right.$ at 1 atmosphere). Only one set of published data was found above $500^{\circ} \mathrm{C}$ (Fig. 26). It revealed that the thermal expansion coefficient, which is the slope of the curves in Fig. 26, is greatly reduced beyond the transition temperature. This reduction is further enhanced by increasing pressure. On the other hand, at temperatures under $500^{\circ} \mathrm{C}$, the pressure dependency of thermal expansion has been shown to be quite small in tests on Climax granite. 93,96 At melting, expansion of 8 to 108 has been reported for granite. 9 Beyond melting, data are very scarce. Volumetric expansion of $4.6 \cdot 10^{-5}$ has been reported for liquid diorite at $1250^{\circ} \mathrm{C} .97$

All the above results are summarized in a simplifled fashion in Fig. 27, which shows the unusual variation of linear expansion with temperature for granite. The effect of pressure is to increase the $\alpha-\beta$ transition temperature. 98 


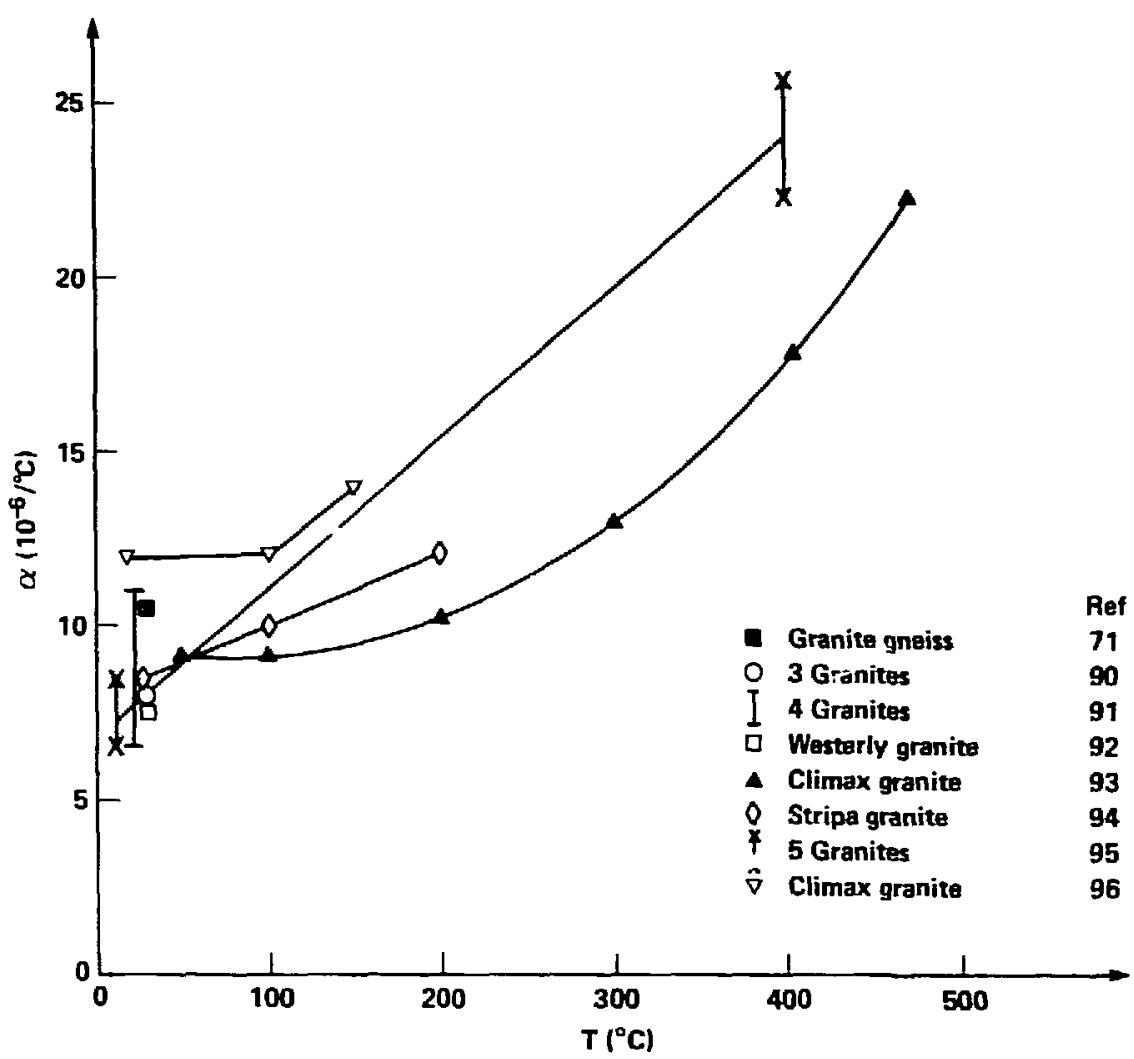

FIG. 25. Thermal expansion coefficient versus temperature for several granites.

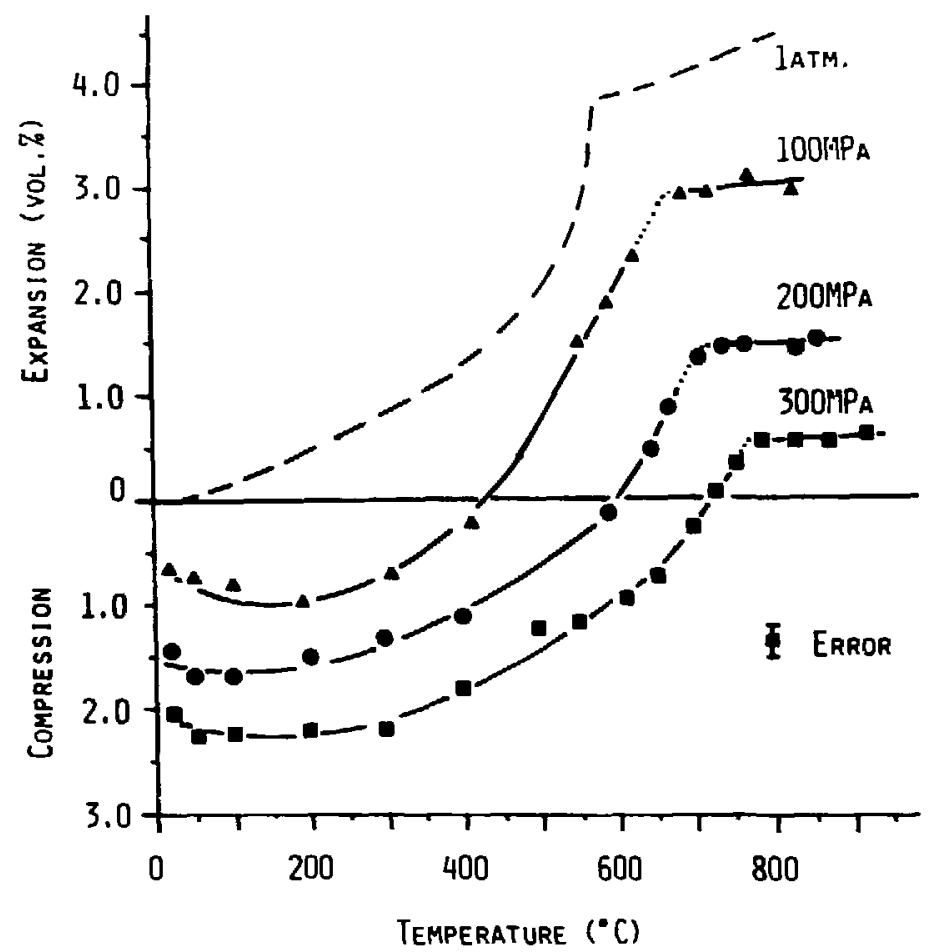

FIG. 26. Expansion of delegate aplite as a function of temperature and pressure. 97 


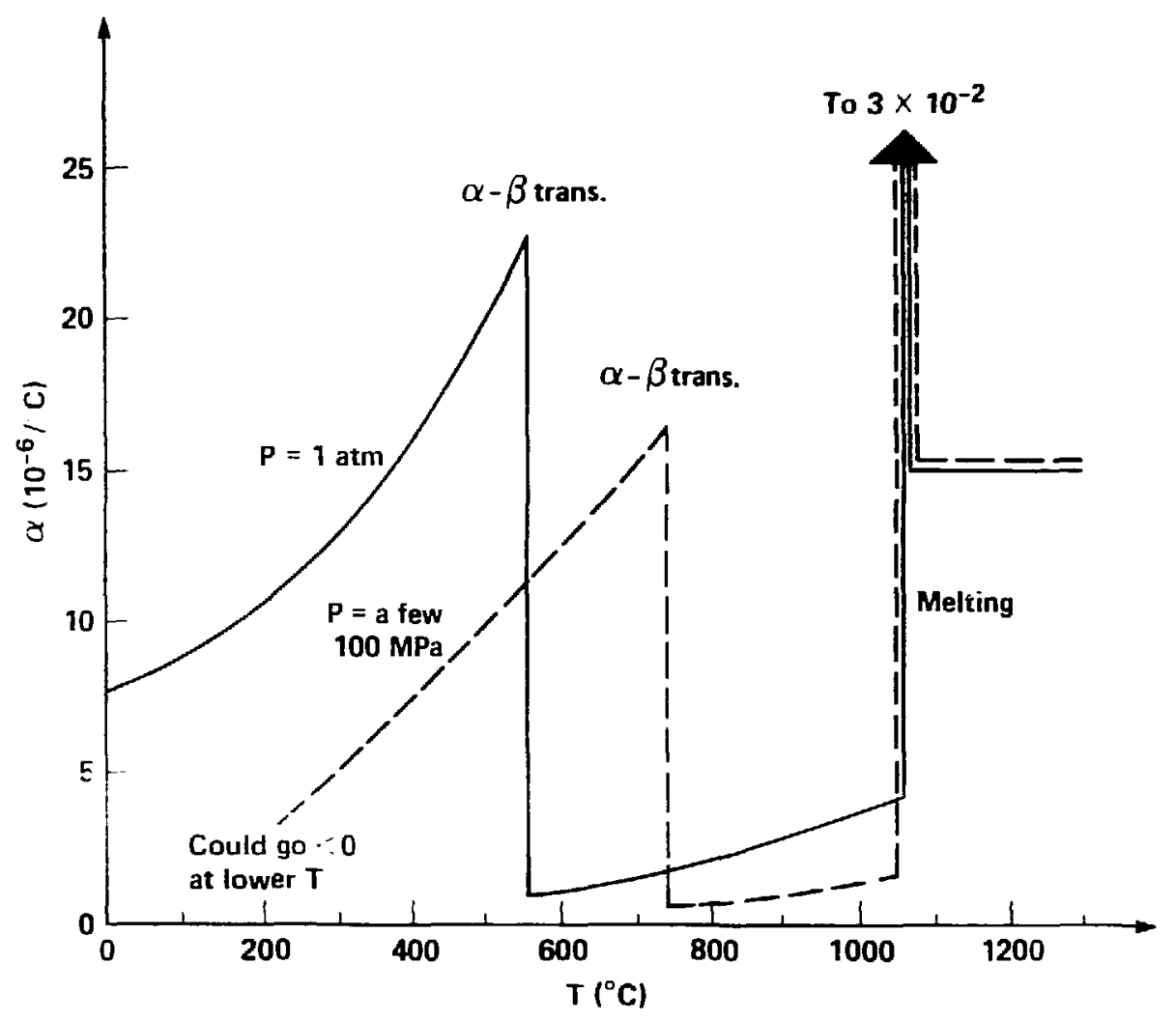

FIG. 27. Schematic of the variation of thermal linear expansion for granite at temperature and pressu

\subsubsection{Viscosity and the Creep Law}

viscosity is one of the key properties in the geotechnical modeling of DRM, but little information is available. It is known that moisture will tend to decrease the melt viscosity. ${ }^{99,100}$ In the granitic formations of interest, the upper limit of water content is about 18 per weight. The few published estimates of granite viscosity versus temperature and moisture content $15,75,101$ are summarized in Table 6 . If the granite melt has access to excess water during its migration, the solution of additional $\mathrm{B}_{2} \mathrm{O}$ in the melt will result in a lowered viscosity. Values of $10^{6}$ to $10^{5} \mathrm{p}$ have been reported between 750 and $850^{\circ} \mathrm{C}$ for a hydrous granite melt with 68 water by weight at $200 \mathrm{MPa} .100$

There is no definite conclusion about the effect of pressure on viscosity. viscosity was reported to be pressure insensitive to $700 \mathrm{MPa}, 101$ whereas it was also reported to increase at pressures up to 1500 MPa and start decreasing 
TABLE 6. Estimated viscosity of granite (P $=\mathrm{g} / \mathrm{cm} \mathrm{s})$.

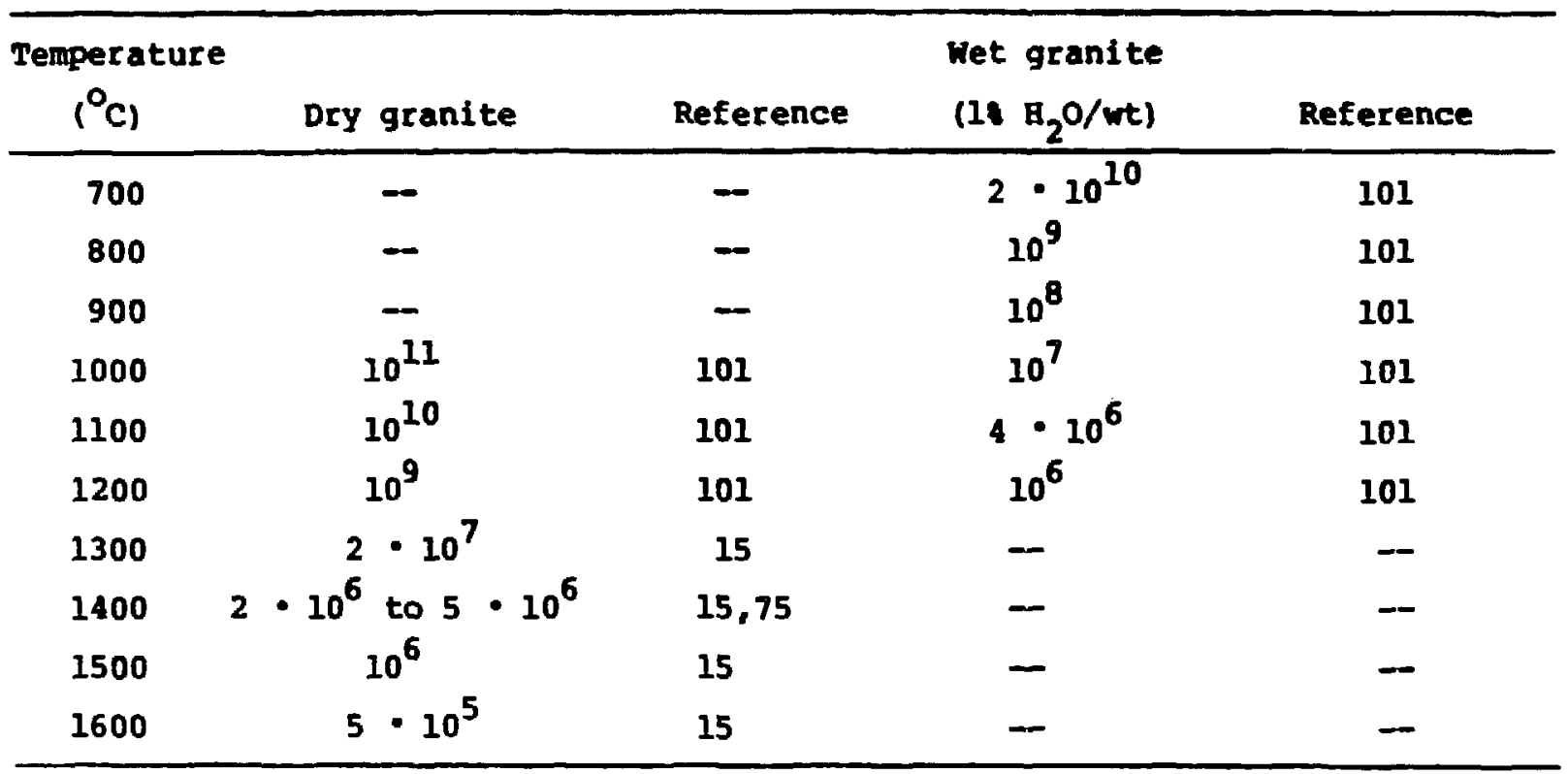

thereafter. 102 Also, it has been noted that the presence of phosphorous can strongly decrease the viscosity of silicate melts. 103

The estimates of viscosity will be used to define the parameters of the creep law. Because of the durations and temperatures involved in DNy, the steady-state creep component will overshadow the transient creep effects. SANGRE and COOPIBFLo use Neertman's law 104,105 for steady-state creep. The only granite for which substantial activation energy data were found is Westerly granite. 106-108 This information is sumarized in Table 7. The latest results for this material also include the presentation of two best-fit creep laws ${ }^{108}$ :

$$
\varepsilon_{t}=7 \cdot 10^{-5} \cdot \sigma^{2.2} \cdot t^{0.5} \cdot \exp \left(-30.5 / \mathrm{RT} \cdot 10^{-3}\right) \text { for transient creep }
$$

and

$$
\dot{E}_{s}=1.4 \cdot 10^{-9} \cdot \exp \left(-25.3 / \mathrm{RT} \cdot 10^{-3}\right) \cdot \sigma^{2.9} \text { for steady-state creep. }
$$

This latest study ${ }^{108}$ also states that high temperature transient creep gives way to steady-state creep at strains less than 18. 
MAIs 7. Activation energy of Festerly granite, as a function of temperature and pressure.

\begin{tabular}{|c|c|c|c|c|c|}
\hline $\begin{array}{c}\text { Reference } \\
\text { date }\end{array}$ & $\begin{array}{c}\text { Range of } \\
\text { temperature } \\
\left({ }^{\circ} \mathrm{C}\right)\end{array}$ & $\begin{array}{c}\text { Range of } \\
\text { differential } \\
\text { stress (LPa) }\end{array}$ & $\begin{array}{c}\text { Range of } \\
\text { confInerent } \\
\text { (IPa) }\end{array}$ & $\begin{array}{l}\text { Dry } \\
\text { or } \\
\text { wet }\end{array}$ & $\begin{array}{c}\text { Activation } \\
\text { energy } \\
\text { (kcal/nole) }\end{array}$ \\
\hline 106,1971 & $430-720$ & $12.8-64.3$ & $400-500$ & Vet $^{1}$ & 78.0 \\
\hline $107 \cdot 1978^{2}$ & $300-500$ & $560-780$ & 250 & Dry & 30.0 \\
\hline $107 \cdot 1978^{2}$ & $500-700$ & $560-780$ & 250 & $\mathbf{D r Y}_{\mathbf{Y}}$ & 85.0 \\
\hline 108, 1901 & $470-765$ & $600-1200$ & 1000 & Dry & $25 \cdot 3^{3}$ \\
\hline Ij8, 1981 & $470-765$ & $600-1200$ & 1000 & Dry & $30.5^{4}$ \\
\hline
\end{tabular}

Notes: 1. 100 KPa pore pressure

2. faulted granite gauge

3. steady-Btate creep

4. transient creep

In studies on quartzite $\mathrm{56}^{509,110}$ it was found that its activation energy was in the range of 38 to $64 \mathrm{kcal} / \mathrm{mole}$, which is comparable to the range of values indicated for Westerly granite. The temperature dependency of viscosity also was much more pronounced for the wet rock than for the dry rock. Such a conclustion probably can apply to granite as well, although the results of Table 7 do not contain direct evidence of this.

\subsubsection{Melting Temperature and Beat of Fusion}

Dry granite wil welt at about $1050^{\circ} \mathrm{C}$, with a gharp boundary between solidus and liquidus. 111 The presence of water makes this boundary mich less defined and lowers the onset of melting.

The latent heat of fusion for granite is commonly taken to be $I=80$ $\operatorname{cel} 1 / 9$. 


\subsubsection{Specific Heat}

The results obtained by different sources are quite consistent. $9,71,112$ Figure 28 shows some discontinuity in the increase of $C_{p}$ with temperature, created by the $\alpha-\beta$ transition. The first power law proposed for $C_{p}(T)^{75}$ did not recognize this feature. In more recent work, ${ }^{112}$ two laws were proposed, one above and one below $573^{\circ} \mathrm{C}$, for each quartz-rich rock tested. All the above data were reported at atmospheric pressure; no results were found at other pressures.

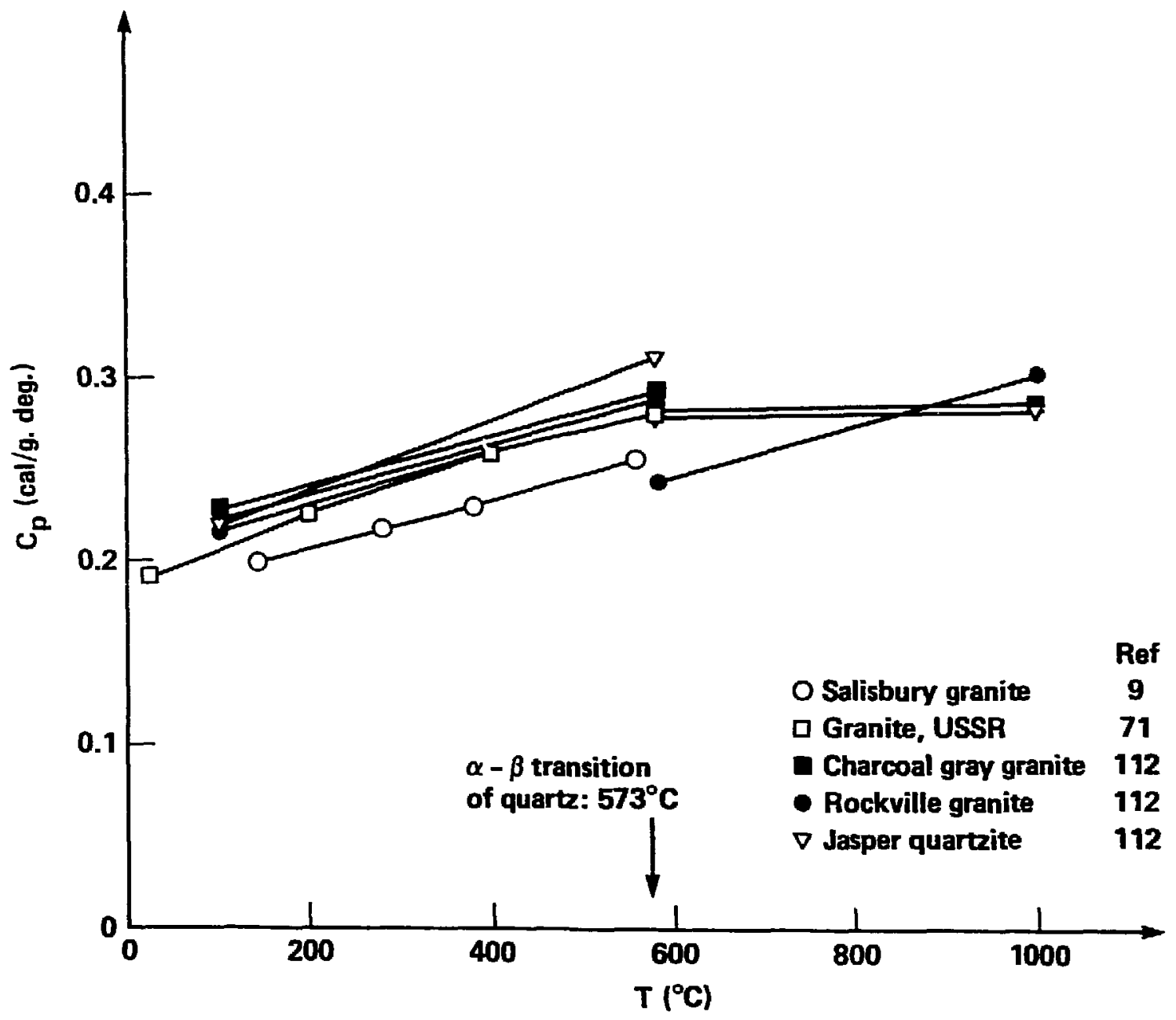

FIG. 28. Specific heat versus temperature for several granites. 


\subsubsection{Thermal Conductivity}

Results for six granites $75,96,113,114$ are shown in Fig. 29. In addition, an empirical $l_{\text {aw }}{ }^{75}$ has been plotted which appears to give a lower bound to the values of $k$. It has the form:

$$
k=6.30 \cdot 10^{-3}-\left(6.7 \cdot 10^{-6} \mathrm{~T}\right)+\left(3.41 \cdot 10^{-9} \mathrm{~T}^{2}\right) \mathrm{cal} / \mathrm{cm}-\mathrm{s}-{ }^{\circ} \mathrm{C}
$$

where $T$ is in ${ }^{\circ} \mathrm{C}$. The validity of the $\mathrm{law}$, at temperatures above $300^{\circ} \mathrm{C}$, has not been determined. It does not show any possible influence of the $\alpha-\beta$ transition.

The results of Fig. 29 were obtained at atmospheric pressure. Tests performed at pressure up to $90 \mathrm{MPa}$ showed a modest increase of $k$ with pressure $^{115}$ (ca 108 over $90 \mathrm{MPa}$ ).

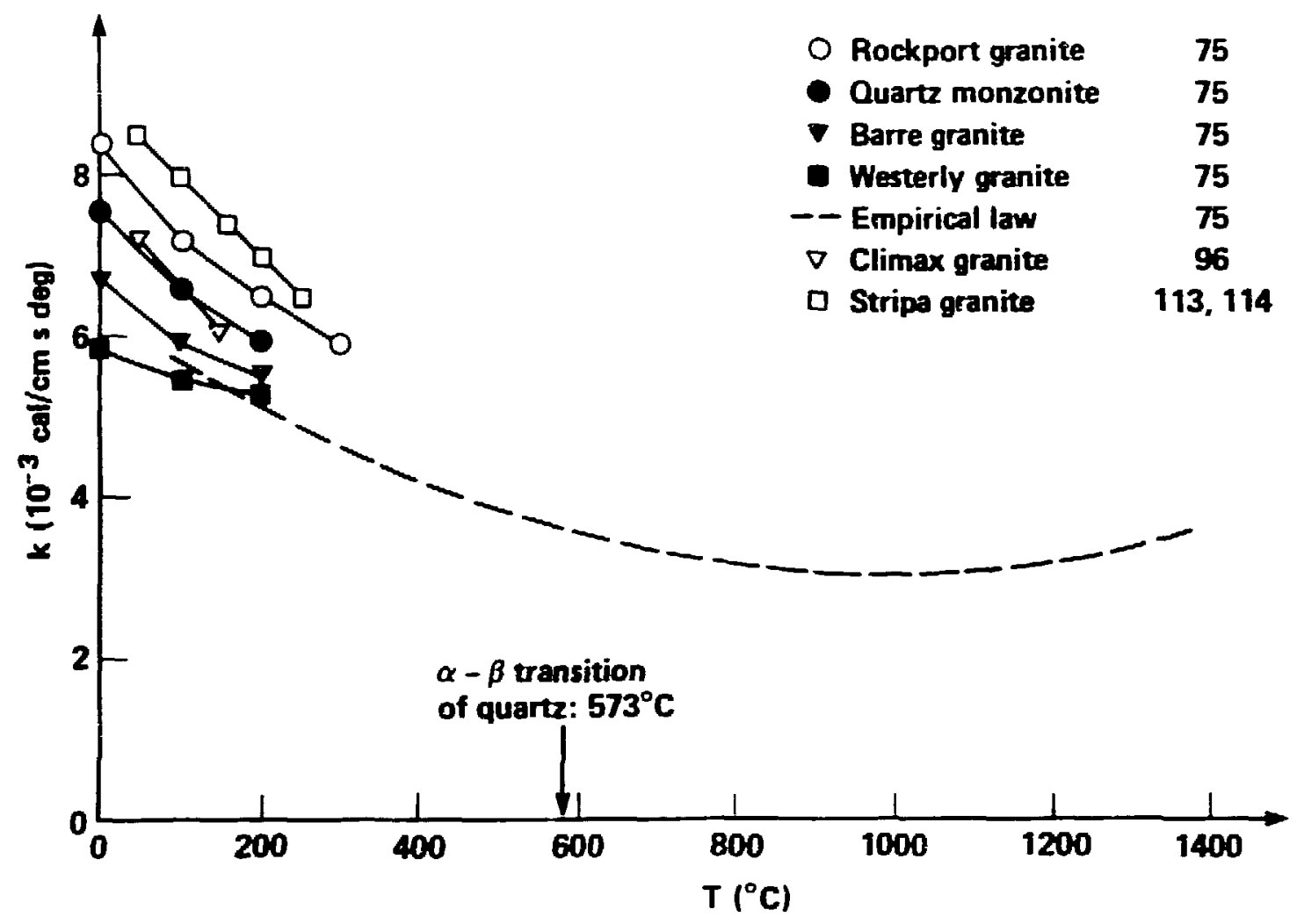

FIG. 29. Thermal conductivity versus temperature for several granites. 


\subsubsection{Thermal Diffusivity}

Results of the survey $96,113,116,117$ are shown in Fig. 30 . Wet materials have a higher thermal diffusivity. The stripa granite also exhibited a 128 higher $K$ in the Eield than in the $1 \mathrm{ab} .113$ The thermal diffusivity data consistently show a minimlin at the $\alpha-\beta$ transition.

All the results in Fig. 30 were obtained at atmospheric pressure. A series of tests on the USBM granite, 117 at pressures down to $10^{-7}$ Torr, showed $K$ decreasing 308 at $27^{\circ} \mathrm{C}$, and 208 at $110^{\circ} \mathrm{C}$, from the corresponding values at atmospheric pressure.

\section{1 .12 Density}

The in situ density of granite bodies is about $2.65 \pm .05 \mathrm{Mg} / \mathrm{m}^{3}$.

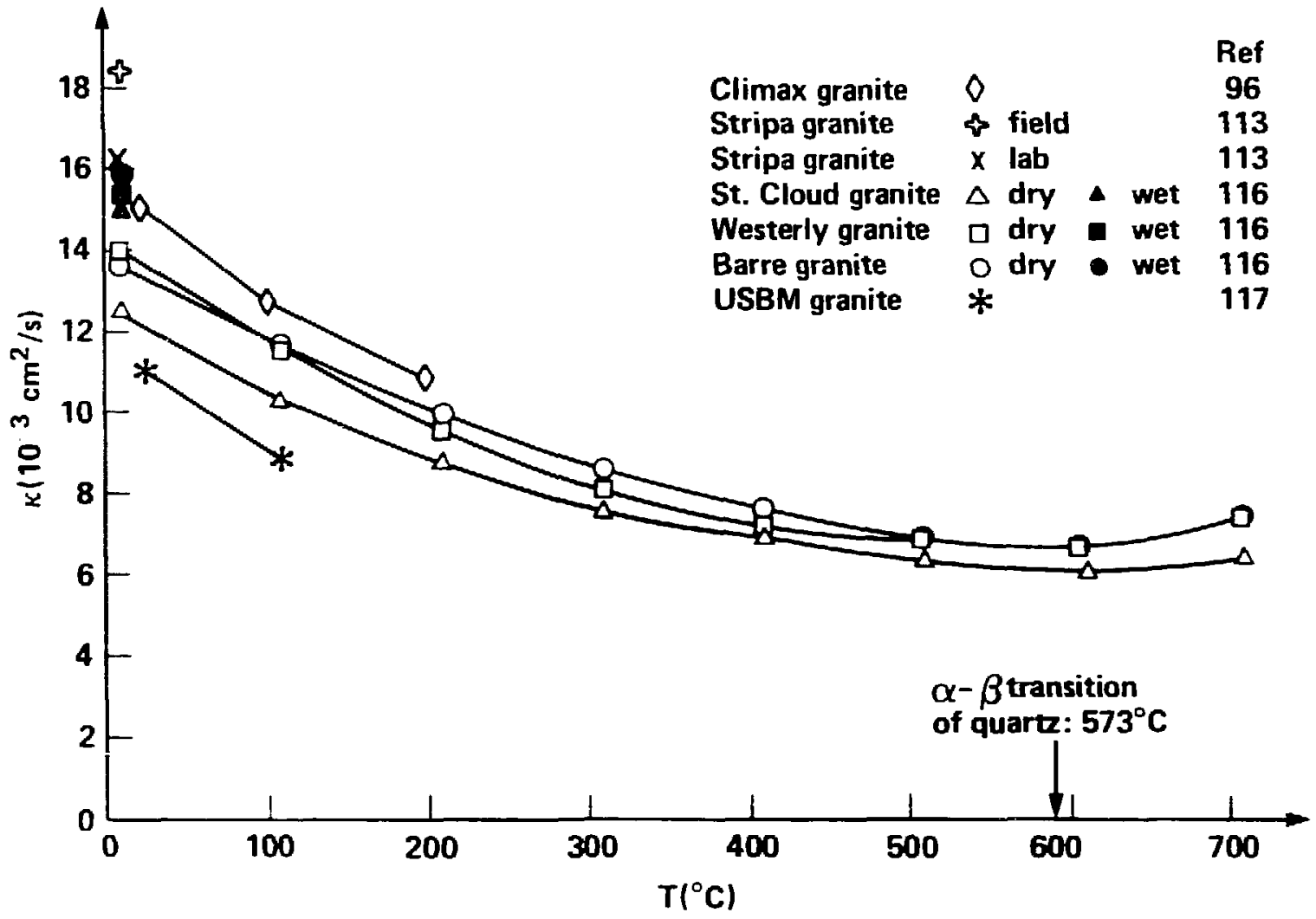

FIG. 30. Thermal diffusivity versus temperature for several granites. 
To sunmarize the state of knowledge on relevant rock mass properties, we adopt an arbitrary grouping in two categories:

- Adequate knowledge: thermal properties $\left(C_{p^{\prime}} k, K, L, T_{m}\right)$; density.

- Inadequate knowledge: compliances $(E, \nu)$; thermal expansion $(\alpha)$ above $500^{\circ} \mathrm{C}$; viscosity $(\mathrm{n})$; in situ strength; in situ permeability $(\mathrm{K})$.

Specific heat, thermal conductivity, and thermal diffusivity values do not differ much between the field and the laboratory. Thermal expansion and viscosity data also can be obtained at reasonable expense in laboratory tests. However, in situ deformability, in situ strength, and in situ permeability require another approach. The cost of field tests makes it very unlikely that one could perform enough tests at a site, on volumes large enough to be representative, so that the field data base would be sufficient. It is more likely that a combined testing and modeling approach will be more successful. Both the joints and the solid materials contribute to deformability, strength, and permeability. Both can be tested individually in medium-sized laboratory or bench-scale tests. Then, these test results will be incorporated into ubiquitous joint models that can simulate the influence of many discontinuities. Such models are under development today. $36,118-120$ Indeed, they will have to be verified with a small number of in situ tests. In the meantime, as outlined in section 3, new parametric studies should be initiated so that the sensitivity of the RDM process to various rock mass properties can be determined. In turn, this will show where to focus new material properties research.

In situ stresses and in situ temperatures are not material properties per se but can be construed as rock mass "properties." For deep siting, it is clear that both quantities will be measured in boreholes which are to be sealed after measurements. The site selection for DRM certainly can be helped by careful temperature profiling. A smoothly varying thermal gradient would suggest the absence of large fractures that are filled with hot fluids ${ }^{121}$ which could provide a path for future radioactive release. 


\section{SUMMARY}

A new strategy has been developed for the geotechnical modeling of nuclear waste disposal by rock melting (DRM). Three separate tasks were performed to reach this objective:

- A review of the four scenarios which have been proposed for DRM, to date.

- An evaluation of computer-based numerical models which could be used to analyze the mechanical, thermal, and hydraulic processes involved in DRM.

- A critical review of rock mass properties relevant to the design and safety of waste disposal by rock melting.

It is concluded that several geotechnical aspects of DRM can be studied realistically with the current state-of-the-art in model capabilities and knowledge of material properties. The next step in the feasibility study of DRM should be a best estimate calculation of the four cavity-melt and canister-burial concepts. The new analyses themselves will indicate what are the most critical areas for subsequent research.

\section{ACRNOWLEDGUENTS}

The author benefited from many discussions with colleagues in and outside of Lawrence Livermore National Laboratory, anong whom C. Anderson, B. Beard, and L. Schwartz deserve special mention.

Mrs. L. Burrow is gratefully acknowledged for her fine typing of the manuscript. 
1. Statement of the Position of the United States Department of Energy in the Matter of Proposed Rulemaking on the Storage and Disposal of Nuclear Wastes (Waste Confidence Rulemaking Document), U.S. Department of Energy, DOE/NE-0007 (April 15, 1980).

2. NWTS Rock Mechanics $R$ and D Technical Plan for Mined Geologic Disposal of Radioactive Waste (formal draft), U.S. Department of Energy, DOE/USGS/ESTP Rock Mechanics Subgroup (June 17, 1980).

3. M. E. Wigley et al., WWTS Rock Mechanics Plan (draft), U.S. Office of Nuclear Waste Isolation, Columbus, OH, ONwI-114 (August 1980).

4. J. J. Cohen et al., In Situ Incorporation of Nuclear Waste in Deep Molten Silicate Rock, Lawrence Livermore National Laboratory, Livermore, CA, UCRL-73320 (1971).

5. J. J. Cohen et al., Economic and Environmental Evaluation of Nuclear Waste Disposal by Underground In Situ Melting, Lawrence Iivermore National Laboratory, Livermore, CA, UCRL-51713 (1974).

6. L. L. Schwartz et al., "High-Level Radioactive waste Isolation by Incorporation in Silicate Rocks," Peaceful Nuclear Explosions $V$, International Atomic Energy Agency, Vienna, Austria, IAFA-TC-81-5/4 (1978).

7. S. E. Logan, "Deep Self-Burial of Radioactive Wastes by Rock Melting Capsules," Transactions of the American Nuclear Society - Annual Meeting Chicago, Illinois, 1973, (American Nuclear Society, Hinsdale, IL) pp. 177-178.

8. H. C. Hardee and . N. Sullivan, An Approximate Solution for Self-Burial Rates of Radioactive Waste Containers, Sandia National Laboratories, Albuquerque, NM, SLA-73-0931 (1974).

9. R. D. Rlett, Deep Rock Nuclear Wasta Disposal Test: Design and Operation, Sandia National Laboratories, Albuquerque, NM, SAND-74-0042 (1974).

10. L. A. Bertram, Mechanics Analysis for Deep Rock Disposal of Radioactive Wastes, Sandia National Laboratories, Albuquerque, NM, SAND-76-007 (1976).

11. J. A. Angelo, Jr., Nuclear Waste Management by In Situ Melting, Ph.D. dissertation, Department of Nuclear Engineering, University of Arizona, Tucson, AZ (University Microfilms, Ann Arbor, MI, 1976). 
12. "Numerical Modeling" (Chapter 9), Rock Mechanics Research Requirements, National Acadeny of Sciences Panel on Rock Mechanics Research Requirements (National Academy Press, Washington, DC, 1981), NRC/AMPS/RH-81-1.

13. D. E. Armstrong et al., Pock Melting as a Drilling Technique, Los Alamos National Laboratory, Los Alamos, NM, LA-3243 (March 1965).

14. E. S. Robinson et al., A Preliminary Study of the Nuclear Subterrene, Los Alamos National Laboratory, Los Alamos, NM, LA-4547 (Apri1 1971).

15. J. C. Rowley, "Rock Melting Applied to Excavation and Tunneling," Proc. $3 r d$ Congress of the International Society for Rock Hechanics, Denver, CO, 1974 (National Academy of Sciences, Washington, DC), vol. II-B, pp. 1447-1453.

16. L. D. Ramspott, Status of LINL Granite Projects, Lawrence Livermore National Laboratory, Livermore, CA, UCRL-84613 (1980).

17. F. E. Heuze, The Climax Granite, Nevada Test Site, as a Host for a Rock Mechanics Test Facility Related to the Geologic Disposal of Bigh-Level Nuclear Wastes, Lawrence Livermore National Laboratory, LIvermore, CA, UCID-18946 (February 1981).

18. M. L. Zoback and M. Zoback, "State of Stress in the Conterminous United States, J. Geophys. Res. 85, 6113-6156 (November 1980).

19. F. E. Heuze, "Scale Effects of the Determination of Rock Mass Strength and Deformability," Rock Mechanics 12, 167-192 (1980).

20. A. L. Edwards, TRUMP: A Computer Program for Transient and Steady-State Temperature Distributions in Multidimensional Systems, Lawrence Livermore National Laboratory, Livermore, CA, UCRL-14754, Rev. 3 (1972).

21. B. Boley, "On a Melting Problem with Temperature-Dependent Properties," Trends in Elasticity and Thermoelasticity (Wolters-Noordhof Publishers, Groningen, The Netherlands, 1971), pp. 23-28.

22. H. C. Haxdee, Natural Convection in a Spherical Cavity with Uniform Internal Heat Generation, Sandia National Laboratorles, Albuquerque, MH, SLA-74-0089 (1974).

23. J. C. Jaeger, Elasticity, Fracture and Flow (Wethuen and Company, Itd., London, England, 1956).

24. J. C. Jaeger, "The Temperature in the Neighborhood of a Cooling Intrusive Sheet, "An. J. Sci. 255, 306-318 (April 1957).

25. A. E. H. Love, The Mathematical Theory of Elasticlty (Dover Publications, New York, NY, 1944). 
26. R. J. Ree et al, Natural Convection of Heat-Generating Fluid within Closed Vertical Cylinders and Spheres, Sandia National Laboratories, Albuquerque, NM, SAND 75-8610 (1975).

27. L. V. Andrew and I. C. Taig, Selection of Structural Analysis Computer Programs, Advisory Group for Aerospace Research and Development, Neuilly, France, Report No. 670 (1979).

28. R. J. Bathe, ADINA: A Finite Element Program for Automatic Dynamic Incremental Non-Linear Analysis, Mechanical Engineering Department, Massachusetts Institute of Technology, Cambridge, MA, MIT-82448-1 (1976).

29. K. J. Bathe, ADINAT: A Finite Element Program for Automatic Dynamic Incremental Non-Linear Analysis of Temperatures, Mechanical Engineering Department, Massachusetts Institute of Technology, Cambriage, MA, MIT-82448-5 (May 1977) .

30. B. Frederiksson et al., "Finite Element programs in Integrated Software for Structural Mechanics and Computer Aided Design (CAD)," Computer Aided Design (January 1981), pp. 27-39.

31. J. O. Hallquist, NIKE-2D: An Implicit, Finite Deformation, Finite Element Code for Analyzing the Static and Dynamic Response of Two-Dimensional Solids, Lawrence Livermore National Labiratory, Livermore, CA, DCRL-52678 (1979).

32. K. H. Huebner, The Finite Element Method for Engineers (Wiley-Interscience, New York, NY, 1975).

33. W. E. Mason, TACO: A Finite Element Heat Transfer Code, Lawrence Livermore National Laboratory, Livermore, CA, UCID-17980 (1978).

34. F. Holzer and L. Ramspott, Eds., Proceedings of a Workshop on Thermo-Mechanical Modeling for a Hardrock Waste Repository, Lawrence Livermore National Laboratory, Livermore, CA, UCRL-10043 (1979).

35. Tabulation of Waste Isolation Computer Models, Volume I (araft report), Science Applications, Inc., Oak Ridge, TN, SAI/OR-749-1 (November 1979).

36. C. F. Tsang, "A Review of the State-of-the-Art of ThermomechanicalHydrochemical Modeling of a Hard Rock Waste Repository," Proc. 2nd Workshop of Thermomechanical-Hydrochemical Modeling for Hard Rock Waste Repositories, July 29-31, 1980, Lawrence Berkeley Laboratory, Berkeley, CA, LBL-11204 (1980), pp. 16-21.

37. M. S. Ayatollahi, P. A. Witherspoon, anc J. Noorishad, A Finite Element Method for Stress and Fluid-Flow Analysis in Fractured Rock Masses, Lawrence Berkeley Laboratory, Berkeley, CA (1980). 
38. J. E. Gale et al., "Flow in Rock with Deformable Fractures," in Finite Element Methods in Flow Problems, J.T. Oden, Ed. (University of Alabama Press, Huntsville, AL, 1974).

39. H. M. Hilber and R. L. Taylor, A Finite Element Model of Fluid Flow in Systems of Deformable Fractures, Report to the National Science Foundation, Department of Civil Engineering, University of California, Berkeley, CA, Publication No. 76-5 (1976).

40. J. W. Mercer, Jr., Finite Element Approach to the Hodeling of Hydrothermal Systems, Ph.D. dissertation, Department of Geology, University of Illinois, Urbana, IL (1973).

41. J. Noorishad et al., A Method for Coupled Stress and Flow Analysis of Fractured Rock Masses, Department of Civil Engineering, University of California, Berkeley, CA, Publication No. 71-6 (1971).

42. A. R. Ingraffea and F. E. Heuze, "Finite Element Models for Rock Fracture Mechanics," Int. J. Numerical \& Analytical Methods in Geomechanics $\underline{4}, 15-43$ (1980).

43. R. B. Demuth and F. H. Harlow, Geothermal Energy Enhancement by Thermal Fracture, Los Alamos National Laboratory, Los Alamos, NM, LA-8428 (1980).

44. J. H. Pitts, Gas-Initiated Crack Propagation in a Porous Solid, Ph.D. dissertation, Lawrence Livermore National Laboratory, Livermore, CA, UCRL-51988 (1976).

45. J. C. Roegiers and J. D. McLennan, Numerical Modeling of Pressurized Fractures, Department of Civil Engineering, University of Toronto, Toronto, Ontario (Canada) Publication No. 78-08 (1978).

46. J. R. Tillerson and M. M. Madsen, Predictions of Crack Motion for Bigh Pressure Gas Fracturization of Geologic Media, Sandia National Laboratories, Albuquerque, NM, SAND-78-0564 (April 1978).

47. B. J. Travis and A. H. Davis, "Calculation of Gas-Driven Fracture Propagation in Rocks," Proc. 20th U.S. Rock Mechanics Symposium, Rolla, MO, 1980 (University of Missouri, Rolla, MO, 1980), pp. 356-361.

48. D. K. Gartling, Finite Element Analysis of Problems in Convective Heat Transfer, Sandia National Laboratories, Albuquerque, NM, SAND 75-0571 (1976).

49. D. K. Gartling, NACHOS: A Finite Element Computer Program for Incompressible Flow Problems. Part I: Theoretical Background, Sandia National Laboratories, Albuquerque, NM, SAND-77-1333 (April 1978). 
50. r. K. Gartling, NACHOS: A Finite Element Computer Program for

Incompressible Flow Problems. Part II: User's Manual, Sandia National Laboratories, Albuquerque, NM, SAND-77-1334 (November 1977).

51. C. Bonacina et al., "Numerical Solution of Phase Change Problems," Int. J. Heat and Mass Transfer 16, 1825-1832 (1973).

52. G. Comini et al., "Finite Element Solution of Non-Linear Heat Conduction Problems with Special Reference to Phase Change," Int. J. Num. Methods in Engineering ㅇ․ 613-624 (1974).

53. D. E. Duncan, Thermo-Mechanical Modeling of the Gas-Tungsten-Arc (GTA) Welding Process, Lawrence Livermore National Laboratory, Livermore, CA, UCRL-52891 (1980).

54. W. C. Erickson, Computer Simulation of Solidification, Los Alamos National Laboratory, Los Alamos, NM, LA-UR-78-1852 (1978).

55. C. A. Anderson and R. J. Bridwell, "A Finite Element Method for studying the Transient Non-Linear Thermal Creep of Geological structures," Int. J. For Numerical and Analytical Methods in Geomechanics $\underline{4}$, 255-276 $(1.980)$.

56. D. R. Parrish et al., "Finite Element Folds of similar Geometry," Iectonophysics 32, 183-207 (1976).

57. T. Shimamoto and I. Hara, "Geometry and Strain Distribution of Single-Layer Folds," Tectonophysics 30, 1-34 (1976).

58. H. Koide and S. Bhattacharji, "Formation of Fractures Around Magmatic Intrusions, and Their Role in Ore Localization," Economic Geology 70 , 781-799 (1975).

59. R. B. Knapp and D. Norton, "Preliminary Numerical Analysis of Processes Related to Magma Crystallization and Stress Evolution in Cooling Pluton Environments," Am. J. SCi. 281 (1), 35-68 (January 1981).

60. R. B. Knapp and J. E. Knight, "Differential Thermal Expansion of Pore Fluids: Fracture Propagation and Microearthquake Production in Hot Pluton Environment," J. Geophys. Res. 82 (17), 2515-2522 (1977).

61. K. H. Lau, Effect of Permeability on Cooling of a Magmatic Intrusion in a Geothermal Reservoir, Lawrence Livermore National Laboratory, Livermore, CA, UCRL-52888 (1980).

62. H. C. Hardee and D. W. Larson, Heat Transfer in Magma Bodies, Sandia National Laboratories, Albuquerque, NM, SAND 76-0011 (1976). 
63. C. A. Anderson, Finite Element Modeling of Long-Term Fluid-Structure Interaction Problems in Geologic Media, Los Alamos National Laboratory, Los Alamos, NH, LA-UR-79-3016 (1980).

64. W. E. Pracht, Implicit Solution of Creeping Flows, with Application to Continental Drift, Los Alamos National Laboratory, Los Alamos, NM, LA-DC-11114 (1970).

65. P. R. Dawson and P. F. Chavez, COJPLEFLO: A Computer Program for Coupled Creeping Viscous Flow, and Conductive-Convective Heat Transfer. Part I: Theoretical Background, Sandia National Laboratories, Albuquerque, NM, SAND-78-1406 (1978) .

66. P. F. Chavez and P. R. Dawson, CoUPLifio: A Computer Program for Coupled Creeping Viscous Flow, and Conductive-Convective Heat Transfer. Part II: User's Manual, Sandia National Laboratories, Albuquerque, NM, SAND-78-1407 (1978).

67. พ. E. Pracht, "A Numerical Method for Calculating Transient Creep Flows," J. Computational Physics 7, 46-60 (1971).

68. A. Sato and E. G. Thompson, "Finite Element Models for Creeping Convection," J. Computational Physics 22, 229-244 (1976).

69. P. R. Dawson, Buoyant Movement of Nuclear Waste Canisters in Marine Sediments, Sandia National Laboratories, Albuquerque, NM, SAND-78-0841 (1978).

70. P. F. Chavez and P. R. Dawson, Thermally Induced Motion of Marine Sediments Resulting from Disposal of Radioactive Wastes, Sandia National Laboratories, Albuquerque, NM, SAND-80-1476 (1981).

71. A. P. Dmitriyev et al., Physical Properties of Rocks at Bigh Temperatures, National Aeronautics and Space Administration Technical Translation, N72-26286 (1972).

72. G. Swan, The Mechanical Properties of Stripa Granite, Lawrence Berkeley Laboratory, Berkeley, CA, LBL-7074 (1978).

73. J. R. Mclaren and I. Titchell, Physical Properties of Granite Relevant to Near Field Conditions in a Nuclear Waste Depository, Atomic Energy Research Establishment, Harwell, Oxfordshire (UK), AERE-R-10046 (January 1981).

74. L. Page and H. C. Heard, Elastic Moduli, Thermal Expansion, and Inferred Permeability of Climax Quartz Monzonite and Sudbury Gabbro to $500^{\circ} \mathrm{C}$ and $55 \mathrm{KPa}$, Lawrence Livermore National Laboratory, Livermore, CA, UCRI-85736 (1981). 
75. S. P. Clark, Jr., Ed., Handbook of Phusical Constants, Geological Society of America, New York, NY, Memoir 97 (1966).

76. S. J. Bauer and B. Johnson, "Effects of Slow Uniform Heating on the Physical Properties of the Westerly and Charcoal Granites," Proc. 20th Symp. on Rock Mechanics, Austin, Texas, 1979 (American Society of Civil Engineers, New York, NY), pp. 7-18.

77. B. K. Atkinson, "Stress Corrosion and the Rate-Dependent Tensile Failure of a Fine-Grained Quartz Rock," Tectonophysics 65, 281-290 (1980).

78. J. Tullis and R. A. Yund, "Experimental Deformation of Dry Westerly Granite," J. Geophys. Res. $\underline{82}$, 5705-5718 (1977).

79. M. Fíiedman et al., "Strength and Ductility of Four Dry Igneous Rocks at Low Pressures, and Temperatures to Partial Melting," Proc. 20th Symp. on Rock Mechanics, Austin, Texas, 1979 (American Society of Civil Engineers, New York, NY), pp. 35-50.

80. R. M. Stesky et al., "Friction in Faulted Rock at High Temperature and Pressure," Tectonophysics 23, 177-203 (1974).

81. S. J. Bauer, M. Friedman, and J. Handin, "Effects of Water Saturation on Strength and Ductility of Three Igneous Rocks at Effective Pressures to $50 \mathrm{MPa}$ and Tenperatures to Partial Melting," Proc. 22nd Symposium on Rock Mechanics, Cambridge, MA, 1981 (Massachusetts Institute of Technology, Cambriage, MA, 1981), pp. 73-78.

82. T. Waza et al., "The Effect of Water on the Subcritical Crack Growth in Silicate Rocks, : Tectonopinysics 67, 25-34 (1980).

83. J. Paquet and P. Francois, "Experimental Deformation of Partially Melted Granitic Rocks at $600-900^{\circ} \mathrm{C}$ and $250 \mathrm{MPa}$ Confining Pressure," Tectonophysics 68, 131-146 (1980).

84. I. Borg and J. Handin, "Experimental Deformation of Crystalline Rock," Tectonophysics $\underline{3}(4), 249-368$ (1966).

85. I. Van der Molen and M. S. Paterson, "Experimental Deformation of Partially Melted Granite," Contrib. Mineral. Petrol. 70, 299-418 (1979).

86. R. Summers, K. Winkler, and J. Byerlee, "Permeability Changes During the Flow of Water Through Westerly Granite, at Temperatures of 100 to $400^{\circ} \mathrm{C}, "$ J. Geophysical Research $\underline{\text { 33}}$ (B1), 339-344 (1978).

87. M. Voegele et al., "Site Characterization of Joint Permeability Using the Heated Block Test," Proc. 22nd Symposium on Rock Mechanics, Cambridge, MA, 1981 (Massachusetts Institute of Technology, Cambridge, MA, 1981), Pp. 120-127. 
88. L. Lundstrom and B. Stille, Large scale permeabllity tests in the granite of the Stripa Mine (Sweden), Lawrence Berkeley Laboratory, Berkeley, CA, LBL-7052 (1978).

89. W. F. Brace, "Permeability of Crystalline and Argillaceous Rocks," Int. J. Rock Mechanics and Mining Science 17, 241-251 (1980).

90. J. N. Sweet, Pressure Effects on Thermal Conductivity and Expansion of Geologic Materials, Sandia National Laboratories, Albuquerque, NM, SAND-78-1991 (1978).

91. D. Richter and G. Simmons, Thermal Expansion Behavior of Igneous Rocks," Int. J. Rock Mechanics and Mining Science 11, 403-411 (1974).

92. T. F. Wong and W. F. Brace, "Thermal Expansion of Rocks: Sane Measurements at Bigh Dressure," Tectonophysics 57, 95-117 (1979).

93. H. C. Heard, "Thermal Expansion and Inferred Permeability of Climax Quartz Monzonite to $300^{\circ} \mathrm{C}$ and $27.6 \mathrm{MPa}, "$ Int. J. Rock Mechanics and Mining science 17, 289-296 (1980).

94. L. Myers, Lawrence Berkeley Laboratory, Berkeley, CA, private comunication (1981).

95. H. W. Cooper and G. Simmons, "The Effects of Cracks on Thermal Bxpansion of Rocks," Barth and Planetary Sclence Ietters 36, 404 (1977).

96. W. B. Durham and A. B. Abey, "The Bffect of Pressure and Temperature on the Thermal Properties of a Salt and a quatz Monzonite, Proc. 22nd Symposium on Rock Mechanics, Cambridge, MA, 1981 (Massachusetts Institute of Technology, Cambridge, MA, 1981), pp. 79-84.

97. B. J. Skinner, "Thermal Bxpansion," Bandbook of Physical Constants, Geological Society of America Memoir 37. Sec. 6, 75-96 (1966).

98. I. Van der Molen, "The Shift of the $\alpha-\beta$ Transition Temperature of Quartz Associated with the Thermal Expansion of Granite at High Pressures," Tectonophysics $73,323-342$ (1981).

99. E. B. Lebedev and N. I. Khitarov, "Dependence of the Beginning of Melting of Granite and of the Electrical Conductivity of its Melt on High Water Vapor Pressure," Geochemistry International 1, 193-197 (1964).

100. B. 0 . Mysen, Melting Curves of Rocks and Viscosity of Rock Forming Melts" (Chapter 11), Physical Properties of Rocks and Minerals, Touloukian and Ho, Eds. (KCGraw Hill, New York, NY, 1981), pp. 361-407.

101. H. R. Shaw, "Coments on viscosity, Crystal settling, and Convection in Granitic Magmas," Am. J. Sc1. 263, 121-152 (1965). 
102. B. O. Mysen et al., "Viscosity of Silicate Melts as a Function of Pressure: Structural Interpretation," Annual Report of the Director, Geophysical Laboratory, Carnegie Institution Yearbook, 1978-1979, pp. 551-556 (December 1979).

103. E. O. Mysen et al., "The Structural Role of Phosphorous in Silicate Melts," Annual Report of the Director, Geophysical Laboratory, Carnegie Institution Yearbook, 1980, pp. 314-315 (December 1980).

104. N. L, Carter and S. H. Kirby, "Transient Creep and Semi-Brittle Behavior of Crystalline Rocks," Pure and Applied Geophysics 116, 807-839 (December 1978).

105. J. Weertman and J. R. Weertman, "High Temperature Creep of Rock and Mantle Viscosity," Annual Review of Earth and Planetary Science $\underline{3}$, 293-315 (1975).

106. C. Goetze, "High-Temperature Rheology of Hesterly Granite," J. Geophys. Res. 76 (5), 1223-1230 (1971).

107. R. M. Stesky, "Mechanism of High Temperature Frictional. Sliding in Westerly Granite," Can. J. of Earth Sciences 15, 361-375 (1978).

108. M. L. Carter, D. A. Anderson, F. D. Hansen, and R. L. Kranz, "Creep and Creep Rupture of Granitic Rocks," Geophysical Monograph 24, pp. 61-82, American Geophysical Union, Washington, D.C. (1981).

109. N. L. Carter, "Steady-State Flow of Rocks," Review of Geophysics and Space Physics 14(3), 301-360 (1976).

110. P. S. Roch et al., "Flow Law of wet quartzite in the $\alpha$-quartz Field," EOS $61(17), 376$ (1980).

111. P. J. Wyllie, The Dynamic Earth (J. Wiley and Sons, New York, NY, 1971).

112. D. P. Lindroth and W. G. Rrawza, Heat Content and Specific Heat of Six Rock Types at Temperatures to $1000^{\circ} \mathrm{C}$, U.S. Bureau of Mines, RI-7503 (1971).

113. J. A. Jeffry et al., Determination of In-Situ Thermal Properties of Stripa Granite, Methods and Preliminary Results, Lawrence Berkeley Laboratory, Berkeley, CA, LBL-8423 (1979).

114. H. Pratt et al., "A Large Scale In-Situ Study to Determine Temperature, Deformation, and Stress Field Associated with Heater Experiments in Crystalline Rocks," Proc. 4th Congress International Society for Rock Mechanics, Montreux, Switzerland 1979 (A.A. Balkema, Rotterdam, The Netherlands, 1979), vol. 2, pp. 539-544. 
115. J. B. Walsh and E. R. Decker, "Effect of Pressure and Saturating Fluids on the Thermal Conductivity of Compact Rock," J. Geophys. Res. 71 (12), 3053-3061 (1966).

116. E. J. Hanley et al., "The Thermal Diffusivity of Bight Well-Characterized Rocks for the Temperature Range 300-1000 K," Bngineering Geology 12, 31-47 (1978).

117. D. P. Lindroth, ThermaI Diffusivity of Six Igneous Rocks at Blevated Temperatures and Reduced Pressures, U.S. Bureau of Mines, RI-7954 (1974).

118. R. R. Thomas, A Material Constitutive Model for Jointed Rock Hass Behavior, Sandia National Laboratories, Albuquerque, NM, SAND-80-1418 (1980).

119. B. C. Trent et al., "A Coupled Gas Pressurization Explicit Fracture Model for Oil Shale Fragmentation," Proc. 22nd Symposium on Rock Mechanics, Cambridge, MA, 1981 (Massachusetts Institute of Technology, Cambridge, MA, 1981), Pp. 198-204.

120. R. D. Hart and C. M. St. John, "A Fully Coupled Thermal-HydraulicMechanical Model for Non-Iinear Geologic Systems," Proc. 22nd Symposium on Rock Mechanics, Cambridge, MA, 1981 (Massachusetts Institute of Technology, Cambridge, MA, 1981), pp. 90-96.

121. T. C. Urban et al., "East Mesa Geothermal Anomaly, Imperial County, California. Significance of Temperature in a Deep Drill Hole Near Thermal Equilibrium," Transactions of the Geothermal Resource Council, Davis, CA, 1978 (Geothermal Resource Council, Davis, CA, 1978), vol. 2, pp. 667-670. 